\title{
STIM1 controls T cell-mediated immune regulation and inflammation in chronic infection
}

\author{
Ludovic Desvignes, ${ }^{1}$ Carl Weidinger, ${ }^{2}$ Patrick Shaw, ${ }^{2}$ Martin Vaeth, ${ }^{2}$ Theo Ribierre, ${ }^{2}$ Menghan Liu, ${ }^{2}$ Tawania Fergus, \\ Lina Kozhaya, ${ }^{2}$ Lauren McVoy, ${ }^{2}$ Derya Unutmaz, ${ }^{1,2}$ Joel D. Ernst,, ${ }^{1,2,3}$ and Stefan Feske ${ }^{2}$ \\ DDepartment of Medicine, 2Department of Pathology, and ${ }^{2}$ Department of Microbiology, New York University School of Medicine, New York, New York, USA.
}

\begin{abstract}
Chronic infections induce a complex immune response that controls pathogen replication, but also causes pathology due to sustained inflammation. $\mathrm{Ca}^{2+}$ influx mediates $\mathrm{T}$ cell function and immunity to infection, and patients with inherited mutations in the gene encoding the $\mathrm{Ca}^{2+}$ channel ORAl1 or its activator stromal interaction molecule 1 (STIM1) are immunodeficient and prone to chronic infection by various pathogens, including Mycobacterium tuberculosis (Mtb). Here, we demonstrate that STIM1 is required for T cell-mediated immune regulation during chronic Mtb infection. Compared with WT animals, mice with T cell-specific Stim1 deletion died prematurely during the chronic phase of infection and had increased bacterial burdens and severe pulmonary inflammation, with increased myeloid and lymphoid cell infiltration. Although STIM1-deficient T cells exhibited markedly reduced IFN- $\gamma$ production during the early phase of Mtb infection, bacterial growth was not immediately exacerbated. During the chronic phase, however, STIM1-deficient T cells displayed enhanced IFN- $\gamma$ production in response to elevated levels of IL-12 and IL-18. The lack of STIM1 in T cells was associated with impaired activation-induced cell death upon repeated TCR engagement and pulmonary lymphocytosis and hyperinflammation in Mtb-infected mice. Chronically Mtb-infected, STIM1-deficient mice had reduced levels of inducible regulatory T cells (iTregs) due to a T cell-intrinsic requirement for STIM1 in iTreg differentiation and excessive production of IFN- $\gamma$ and IL-12, which suppress iTreg differentiation and maintenance. Thus, STIM1 controls multiple aspects of T cell-mediated immune regulation to limit injurious inflammation during chronic infection.
\end{abstract}

\section{Introduction}

Modulation of intracellular $\mathrm{Ca}^{2+}$ concentrations is an important mechanism for regulating the function of many immune cells, especially $\mathrm{T}$ cells (1). In response to antigen binding to the $\mathrm{T}$ cell receptor (TCR), $\mathrm{Ca}^{2+}$ is released from ER stores. The subsequent decrease in the $\mathrm{ER} \mathrm{Ca}^{2+}$ concentration is sensed by stromal interaction molecule 1 (STIM1) and its homologue STIM2, which translocate and bind to ORAI1 in the plasma membrane. ORAI1 is the pore-forming subunit of the $\mathrm{Ca}^{2+}$ release-activated $\mathrm{Ca}^{2+}$ (CRAC) channel. Binding of STIM1 to ORAI1 opens the CRAC channel, which mediates sustained $\mathrm{Ca}^{2+}$ influx from the extracellular space. This form of $\mathrm{Ca}^{2+}$ influx is called store-operated $\mathrm{Ca}^{2+}$ entry (SOCE) and controls numerous $\mathrm{Ca}^{2+}$-dependent signaling events, including activation of transcription factors of the nuclear factor of activated T cells (NFAT) family and expression of cytokine genes in human and murine T cells (2). Accordingly, T cells from mice with conditional deletion of Stim1 or both Stim1/Stim 2 genes have severely reduced production of IFN- $\gamma$, IL-2, and other cytokines. T cell-specific deletion of Stim1/Stim2 results in increased susceptibility to acute viral infection with lymphocytic choriomeningitis virus (LCMV) (3) and impaired antitumor immunity (4) due to perturbed $\mathrm{CD}^{+} \mathrm{T}$ cell effector

Authorship note: Ludovic Desvignes and Carl Weidinger contributed equally to this work. Conflict of interest: Stefan Feske is a cofounder of CalciMedica.

Submitted: December 1, 2014; Accepted: April 2, 2015.

Reference information: J Clin Invest. 2015;125(6):2347-2362. doi:10.1172/JCI80273. functions. Furthermore, both $\mathrm{CD}^{+}$and $\mathrm{CD} 8^{+} \mathrm{T}$ cells require SOCE mediated by STIM1/STIM2 to sustain memory CD8 ${ }^{+}$ $\mathrm{T}$ cell response to acute viral infection (3). Patients (PATs) with inherited mutations in ORAI1 or STIM1 genes that abolish SOCE develop a SCID-like disease termed CRAC channelopathy $(5,6)$. Although T cell development is normal, PATs' $\mathrm{CD}^{+}$and $\mathrm{CD} 8^{+}$ $\mathrm{T}$ cells proliferate poorly after TCR stimulation in vitro and have reduced production of IFN- $\gamma$ and other cytokines (7-9). Impaired $\mathrm{T}$ cell functions result in chronic bacterial and viral infections (7-13). Furthermore, several SOCE-deficient PATs vaccinated with attenuated Mycobacterium bovis (bacillus Calmette-Guerin [BCG]) displayed pathologic lymphoproliferation (ref. 7 and S. Feske, unpublished observations), suggesting that SOCE may also be required for orchestrating immune regulatory functions in response to mycobacterial infections.

Tuberculosis (TB) is a chronic infection caused by Mycobacterium tuberculosis $(M t b)$ and represents one of the most common causes of infection-related death worldwide. Following deposition in lung alveoli, $M t b$ infects alveolar macrophages (AM) and other lung myeloid cells, i.e., neutrophils, DCs, and recruited interstitial macrophages (RIM) (14). Despite active mechanisms of immune evasion deployed by $M t b$, a delayed adaptive immune response is established in the lung-draining lymph node, and effector $\mathrm{T}$ cells migrate to the lungs (15). There, display of $M t b$ antigens, TCR, and costimulatory signals, together with signals received from IL-12, IL-18, and other cytokines produced by myeloid cells, results in the production of IFN- $\gamma$ by T cells $(14,16-18)$. In turn, IFN- $\gamma$ activates 
myeloid cells to kill intracellular mycobacteria, although additional evasion mechanisms limit the effectiveness of this response and lead to $M t b$ persistence $(14,19)$. The importance of IFN- $\gamma$ for antimycobacterial immunity is emphasized by Ifng ${ }^{-/-}$mice, in which $M t b$ causes disseminated infection and early mortality $(20,21)$. PATs with mutations in IL12B, IL12RB1, IFN-GR1, IFN-GR2, or STAT1 genes that impair IL-12/IFN- $\gamma$-dependent signaling between $\mathrm{CD}^{+} \mathrm{T}$ cells and myeloid cells have an increased susceptibility to systemic infections with low virulence mycobacteria $(17,22)$. Despite the protective role of IFN- $\gamma$ in early TB, PATs with high levels of IFN- $\gamma$ seem more likely to progress to active disease (17), suggesting that IFN- $\gamma$ levels during chronic infection correlate better with bacterial burden than with bacterial control.

During chronic infections, T cells are continuously activated by persistent pathogens (23). Mtb-infected macrophages and other myeloid cells induce $\mathrm{T}$ cells to continuously produce cytokines such as IFN- $\gamma$ or TNF- $\alpha$ (19), thus contributing to chronic lung inflammation. Therefore, $\mathrm{T}$ cell activation is tightly regulated to prevent excessive tissue damage in the course of chronic TB (24). Mechanisms limiting sustained immune responses and immunopathology associated with chronic infection and inflammation include signaling through inhibitory receptors such as PD-1 (25), activation-induced cell death (AICD or apoptosis) in T cells (26-28), and regulatory T cells (Tregs) that express the lineage-specific transcription factor FOXP3 $(29,30)$. However, the ambiguous role of Tregs in delaying the onset and/or limiting the efficiency of the adaptive immune response to $M t b$ has attracted most of the attention in the field, and little is known about their role in controlling inflammation during chronic infection (31).

To investigate the role of SOCE in immunity to $M t b$ and the immune regulation of chronic infection, we studied $M t b$ infection in mice with conditional deletion of Stim1 in T cells. We found that, while STIM1-mediated $\mathrm{Ca}^{2+}$ influx is required for optimal production of IFN- $\gamma$ in early $M t b$ infection, it mostly plays important immune regulatory functions in T cells during chronic $M t b$ infection, thereby limiting injurious pulmonary hyperinflammation. Taken together, our results show that STIM1 is a critical regulator of $\mathrm{T}$ cell responses in chronic infection.

\section{Results}

STIM1 in T cells is required to control chronic Mtb infection in mice. To investigate the role of STIM1 in adaptive immunity to chronic infection, we infected WT and Stim $1^{f l / f l} \mathrm{Cd} 4$-Cre $\left(\operatorname{Stim} 1^{C D 4}\right)$ mice, whose $\mathrm{CD}^{+}{ }^{+}$and $\mathrm{CD} 8^{+} \mathrm{T}$ cells lack SOCE (ref. 32 and Supplemental Figure 1A; supplemental material available online with this article; doi:10.1172/JCI80273DS1), with aerosolized Mtb. Unexpectedly, Stim $1^{C D 4}$ mice survived the acute phase of infection, but died significantly earlier than WT littermates during chronic $M t b$ infection (median survival time: 149 days post infection [d.p.i.] vs. 240 d.p.i.; Figure 1A). Premature mortality of Stim $1^{C D 4}$ mice was accompanied by very high lung bacterial burdens at late (>70 d.p.i.) but not early (<45 d.p.i.) stages of infection when compared with WT mice (Figure 1B). By 114 d.p.i., when Stim $1^{C D 4}$ mice started to die, their lungs harbored 37 times more bacteria than WT mice. The lungs of chronically infected Stim1 $1^{C D 4}$ mice showed pronounced inflammation and consolidation, with increased cellularity as early as 45 d.p.i. and reduced alveolar spaces by 114 d.p.i. when compared with infected WT littermates and uninfected Stim $1^{\mathrm{CD} 4}$ mice (Figure 1, C-E).

At late stages of infection (114 d.p.i.), the lungs of $M t b$-infected mice contained large numbers of $\mathrm{CD}^{2} 8^{+}$monocytes/macrophages (Figure 2A). Whereas myeloid infiltrates were focal in WT mice, delineating a classic pulmonary granulomatous response, the lungs of Stim $1^{C D 4}$ mice were diffusely infiltrated with $\mathrm{CD} 68^{+}$ cells. Flow cytometry analysis revealed that numbers of AM, neutrophils, monocytes, and RIM were already elevated by 45 d.p.i. in the lungs of $M t b$-infected Stim $1^{C D 4}$ mice compared with infected WT littermates (Figure 2, B-D). This was in contrast to uninfected Stim $1^{C D 4}$ mice, which showed a size and composition of lung myeloid cell populations comparable to those of uninfected WT mice (Supplemental Figure 1B). Later in the course of $M t b$ infection, myeloid cells accumulated even more substantially in the lungs of $M t b$-infected Stim $1^{C D 4}$ mice and, by 114 d.p.i., most populations, including myeloid DCs ( $\mathrm{mDC})$, were significantly $(P<0.05)$ increased. Additionally, levels of myeloid growth factors, inflammatory cytokines, and chemokines, such as IL-1 $\beta$, MCP-1, MIP-1 $\alpha$, and RANTES, were markedly increased in the lungs of $M t b$-infected Stim $1^{C D 4}$ mice compared with WT controls (Figure 2E). These findings demonstrate that, in the absence of STIM1 in T cells, $M t b$ infection results in an early onset, progressive pulmonary hyperinflammation that culminates during the chronic phase of infection.

STIM1 controls AICD of T cells during chronic infection. In addition to infiltration by myeloid cells, the lungs of $M t b$-infected Stim $1^{C D 4}$ mice showed strong infiltration by $\mathrm{CD}^{+} \mathrm{T}$ cells compared with WT littermates (Figure 3A). Pulmonary infiltrates in Stim $1^{C D 4}$ mice contained significantly more $\mathrm{CD} 4^{+}$and $\mathrm{CD} 8^{+} \mathrm{T}$ cells than in WT mice as early as 45 d.p.i. and throughout $M t b$ infection (Figure 3B). Notably, lung T cell numbers were comparable in WT and Stim $1^{C D 4}$ mice before infection. These findings indicate that proliferation of $\mathrm{T}$ cells in vivo and their ability to home to sites of infection are independent of SOCE, confirming previous findings that SOCE is not required for $\mathrm{T}$ cell homing to secondary lymphoid organs or tumors $(4,33)$. During chronic infection, $\mathrm{T}$ cells continuously encounter antigen and are repeatedly stimulated through their TCR. To mimic this recurring antigen exposure and investigate the role of STIM1 in T cell homeostasis, we repeatedly stimulated $\mathrm{CD} 4^{+}$and $\mathrm{CD} 8^{+} \mathrm{T}$ cells from uninfected $\mathrm{WT}$ and Stim $1^{C D 4}$ with $\alpha C D 3$ in vitro. Repeated TCR stimulation induced a rapid decline in absolute numbers of $\mathrm{CD}^{+}$and $\mathrm{CD} 8^{+} \mathrm{T}$ cells from WT mice, whereas STIM1-deficient T cells expanded vigorously (Figure 3C). T cells continuously encountering antigen in vivo undergo AICD, thereby limiting the immune response (26). We observed significantly reduced frequencies of annexin $\mathrm{V}^{+}$apoptotic cells among $\alpha \mathrm{CD} 3$-restimulated $\mathrm{CD}^{+}$and $\mathrm{CD} 8^{+} \mathrm{T}$ cells from Stim $1^{C D 4}$ mice compared with those from WT littermates (Figure $3, \mathrm{D}$ and $\mathrm{E}$ ). To confirm that SOCE also regulates AICD in human T cells, we used $\mathrm{CD} 4^{+}$and $\mathrm{CD} 8^{+} \mathrm{T}$ cells from a PAT with an ORAI1 p.R91W loss-of-function mutation that abolishes SOCE (Supplemental Figure 2A and ref. 10). Restimulation of the PAT's T cells with $\alpha \mathrm{CD} 3 / \alpha \mathrm{CD} 28$ showed a resistance to AICD similar to that found with STIM1-deficient mouse $\mathrm{T}$ cells (Figure 3F). These findings demonstrate that STIM1 is required for TCR-mediated apoptosis of $\mathrm{T}$ cells following repeated stimulation. 

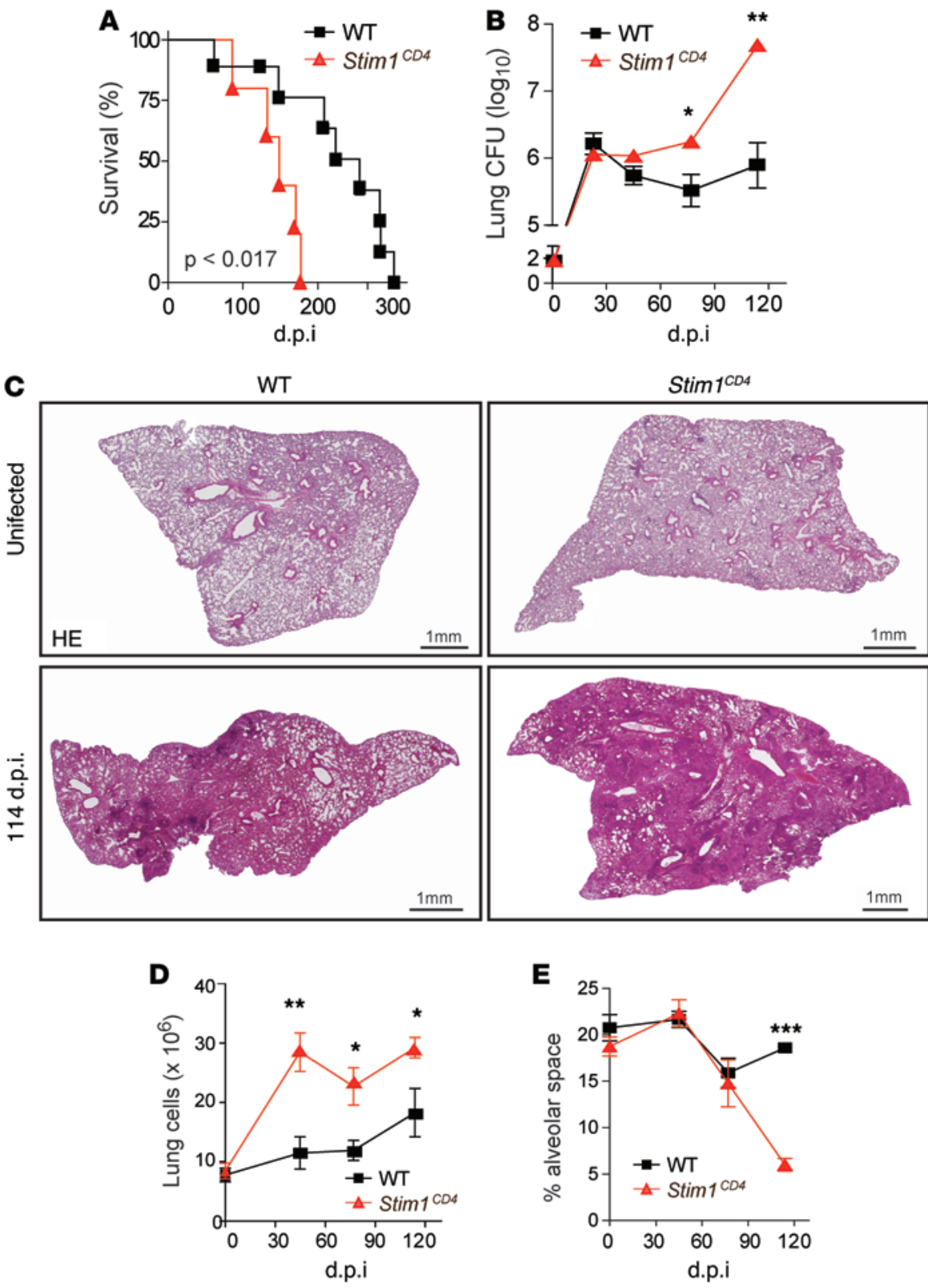

Figure 1. STIM1 in T cells is required to control chronic Mtb infection in mice. (A and B) Survival curves (A) and lung bacterial burden (B) of Stim $7^{104}$ and WT control mice infected with 100 CFU of aerosolized Mtb strain H37Rv. Results are representative of 3 independent experiments. (C) $\mathrm{H} \& \mathrm{E}$ stains of lung sections at 114 d.p.i. Pictures are representative of 5 mice per group. Original magnification, $\times 40$. (D) Averaged total numbers of live cells isolated from the lungs of 3 to 5 mice per group and time point. (E) Open alveolar spaces quantified from histological sections in part $\mathbf{C}$ of 4-5 mice per group and time point using ImageJ software. Statistical significance was calculated by Student's $t$ test. ${ }^{*} P<0.05$; ${ }^{* *} P<0.01 ;{ }^{* *} P<0.001$.

during chronic $M t b$ infection in vivo, we analyzed mRNA expression of proapoptotic factors, normalized to $C d 4$ and $C d 8$ mRNA expression, in lung homogenates of WT or Stim $1^{C D 4}$ at 77 d.p.i. We observed significantly decreased expression of several proapoptotic factors, including Fas, FasL, and NOXA, in the lungs of Stim $1^{\text {CDA }}$ mice compared with littermate controls during chronic infection (Figure 4D). Our data demonstrate that STIM1 and SOCE regulate expression of proapoptotic factors in $\mathrm{T}$ cells and function as inducers of AICD following repeated TCR stimulation. This mechanism may explain how, in the absence of STIM1 and thereby AICD, $\mathrm{T}$ cells expand unchecked in the lungs of $M t b$-infected mice.

Dual role of STIM1 in TCR- and IL-12/ IL-18-induced IFN- $\gamma$ production. IFN- $\gamma$ is critical for controlling mycobacterial infections $(20,22)$, notably via activation of macrophages to kill phagocytosed mycobacteria $(35,36)$. Early during $M t b$ infection ( 45 d.p.i.), we found significantly reduced IFN- $\gamma$ levels in lung supernatants

To further investigate the role of STIM1 in the regulation of $\mathrm{AICD}$, we analyzed gene-expression profiles in $\mathrm{CD} 4^{+} \mathrm{T}$ cells from WT or Stim $1^{C D 4}$ mice after TCR stimulation. Pathway analysis of molecules differentially regulated in STIM1-deficient compared with WT $\mathrm{CD} 4^{+} \mathrm{T}$ cells revealed downregulation of numerous proapoptotic factors including Fas ligand (FasL), TRAIL, NUR77, and $\mathrm{BIM}$, whereas no equivalent upregulation of proapoptotic molecules, except CASP6, was observed (Figure 4A). FasL protein expression was also reduced in STIM1-deficient $\mathrm{T}$ cells compared with WT controls after $\alpha \mathrm{CD} 3$ restimulation and correlated strongly with decreased frequencies of annexin $\mathrm{V}^{+}$apoptotic $\mathrm{T}$ cells (Figure 4B). A similar reduction of FASLG mRNA expression was observed in T cells of the ORAI1-deficient PAT after PMA/ionomycin or $\alpha \mathrm{CD} 3 / \alpha \mathrm{CD} 28$ restimulation in vitro (Figure $4 \mathrm{C}$ ), consistent with regulation of FasL expression by SOCE $(4,34)$. To determine whether STIM1 regulates proapoptotic factors in $\mathrm{T}$ cells of Stim $1^{C D 4}$ mice (Figure 5A) and impaired IFN- $\gamma$ production by isolated STIM1-deficient $\mathrm{CD} 4^{+}$and $\mathrm{CD} 8^{+} \mathrm{T}$ cells compared with WT controls (Figure 5B). This is consistent with our previous observations that SOCE is required for TCR-mediated IFN- $\gamma$ production by human and mouse T cells in vitro $(32,37,38)$. Surprisingly, however, lower IFN- $\gamma$ levels in the lungs of Stim $1^{\mathrm{CD} 4}$ mice were not accompanied by higher bacterial burdens (Figure 1B). To explain this discrepancy, we compared IFN- $\gamma$ production and bacterial loads in $M t b$-infected WT, Ifng heterozygous (Ifng $g^{+-}$), and Ifng null (Ifng--) mice (Supplemental Figure 3). As expected, Ifng ${ }^{-1}$ mice failed to control bacterial growth and had approximately 10 -fold increased pulmonary bacterial burdens as well as significantly $(P<0.05)$ larger pulmonary cellularity at 35 d.p.i compared with WT controls. Although Ifng ${ }^{+>}$mice showed a significantly $(P<0.01)$ reduced frequency of IFN- $\gamma$-producing $\mathrm{CD} 4^{+} \mathrm{T}$ cells compared with WT controls, their pulmonary cellularity was 
A
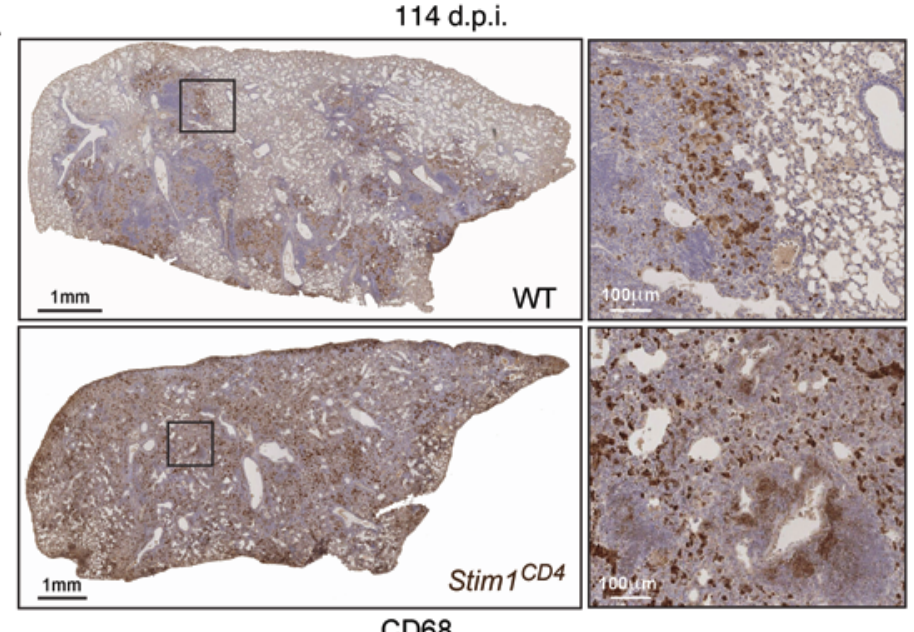

CD68
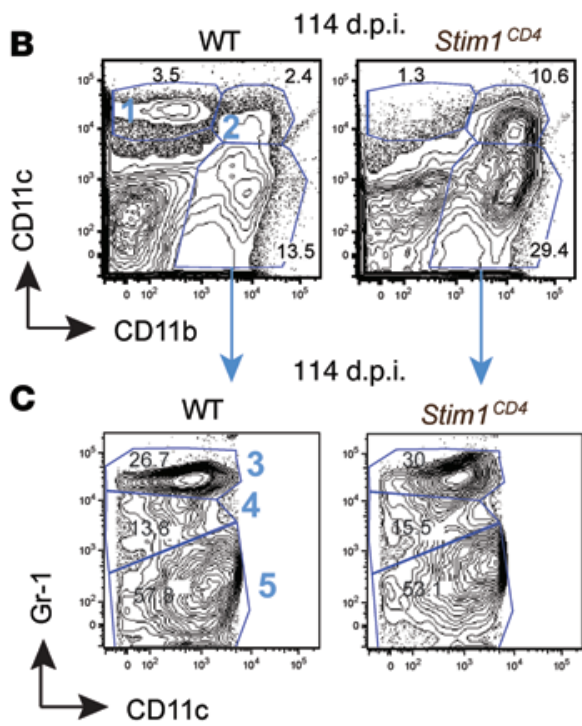
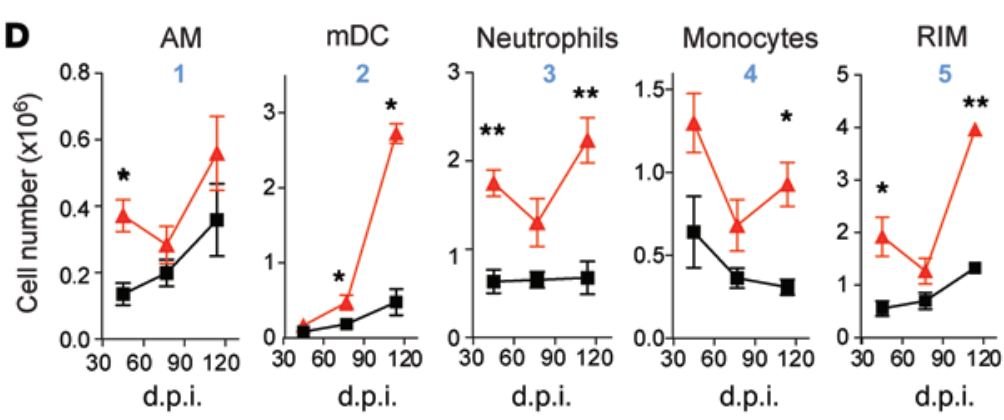

$-\mathrm{WT} \leftarrow \operatorname{Stim} 1 \mathrm{CO4}$

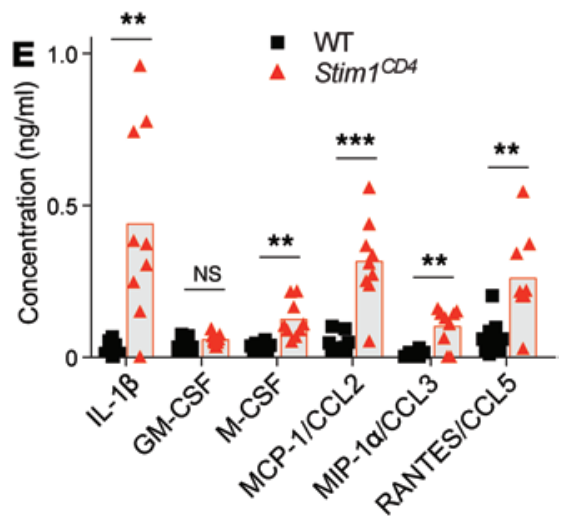

Figure 2. STIM1 in T cells controls myeloid cell infiltration of Mtb-infected lungs. (A) Immunohistochemistry of CD68 expression on monocytes/ macrophages in lungs of $M t b$-infected mice at 114 d.p.i. Images are representative of 5 mice per group. Original magnification, $\times 40$ (left panels); $\times 400$ (right panels). (B and C) Frequencies of lung myeloid cell populations at 114 d.p.i. Representative flow cytometry plots of 5 mice per group analyzed.

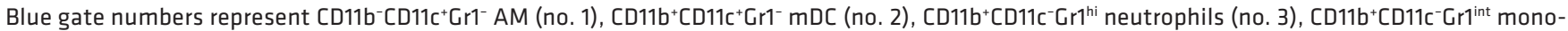
cytes (no. 4), and CD11b+CD11c-Gr1- RIM (no. 5). (D) Absolute numbers of myeloid cell populations in the lungs of WT and Stim $7^{C D 4}$ mice (as defined in B and $\mathbf{C}$ ) over the course of $M t b$ infection. Line graphs show mean \pm SEM of 5 mice per group and time point. (E) Concentrations of the proinflammatory cytokine IL-1 $\beta$, myeloid growth factors (CM-CSF, M-CSF), and chemokines (MCP-1/CCL2, MIP-1 $\alpha / C C L 3$, RANTES/CCL5) in lung homogenate supernatants from Mtb-infected WT and Stim $7^{\mathrm{CD} 4}$ mice analyzed at 107 d.p.i. and 114 d.p.i. by multiplex analysis. Individual values for both days are pooled and indicated by symbols. Bar graphs show the mean of 9 mice ( 4 on 107 d.p.i. and 5 on 114 d.p.i.) per group. Statistical significance was calculated by Student's $t$ test. ${ }^{*} P<0.05 ;{ }^{*} P<0.01 ;{ }^{* *} P<0.001$.

comparable, and they were equally able to control $M t b$ in their lungs. These results indicate that, although IFN- $\gamma$ is essential for protection against $M t b$, it is produced in excess of what is needed for immunity and suggest that the reduced, but not absent, IFN- $\gamma$ production by STIM1-deficient T cells is sufficient to control $M t b$ during acute infection.

Unexpectedly, IFN- $\gamma$ levels increased in the lung supernatants of Mtb-infected Stim $1^{C D 4}$ mice as the infection became chronic (>77 d.p.i.) and exceeded those in WT mice (Figure 5A). Additionally, STIM1-deficient $\mathrm{CD} 4^{+}$and $\mathrm{CD} 8^{+} \mathrm{T}$ cells isolated at 114 d.p.i. produced similar or increased amounts of IFN- $\gamma$ compared with WT controls upon restimulation ex vivo (Figure 5B). These findings suggest that IFN- $\gamma$ production by T cells becomes independent of TCR stimulation and SOCE during chronic $M t b$ infection. IL-12 and IL-18 produced by myeloid cells synergize to induce IFN- $\gamma$ in T cells (39), and continuous production of IL-12 is required to maintain Th1 cells in the lungs of chronically $M t b-$ infected mice (40). We found that the lung levels of IL-12p70 and IL-18 were strongly elevated in $M t b$-infected Stim $1^{C D 4}$ mice at 114 d.p.i. compared with those of WT controls (Figure 5C). Importantly, ex vivo restimulation of isolated $\mathrm{CD}^{+}{ }^{+}$and $\mathrm{CD} 8^{+} \mathrm{T}$ cells with IL-12 and IL-18 resulted in increased IFN- $\gamma$ production by STIM1-deficient T cells compared with WT controls (Figure 5D).

We next asked whether STIM1-deficient $\mathrm{T}$ cells might be intrinsically more responsive to IL-12/IL-18 than WT T cells. $\mathrm{CD} 4^{+} \mathrm{T}$ cells from uninfected Stim $1^{\mathrm{CD} 4}$ mice are severely impaired in their ability to express IFN- $\gamma$ (and TNF- $\alpha$ ) after PMA/ionomycin treatment that mimics TCR stimulation, but unexpectedly produced significantly more IFN- $\gamma$ (and TNF- $\alpha$ ) upon IL-12/ IL-18 stimulation in vitro than WT CD $4^{+} \mathrm{T}$ cells (Figure $5 \mathrm{E}$ ). This 
A

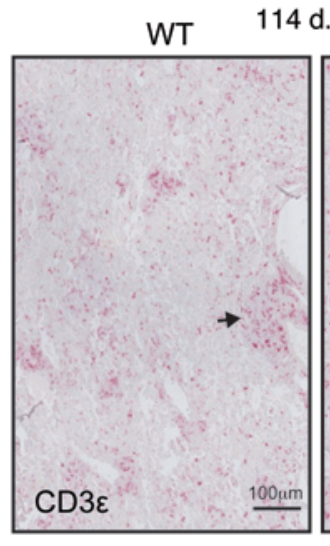

114 d.p.i.

Stim $1^{\text {CDd }}$

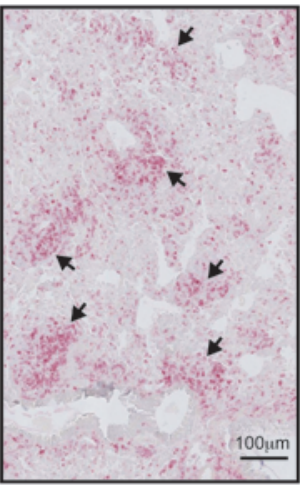

B

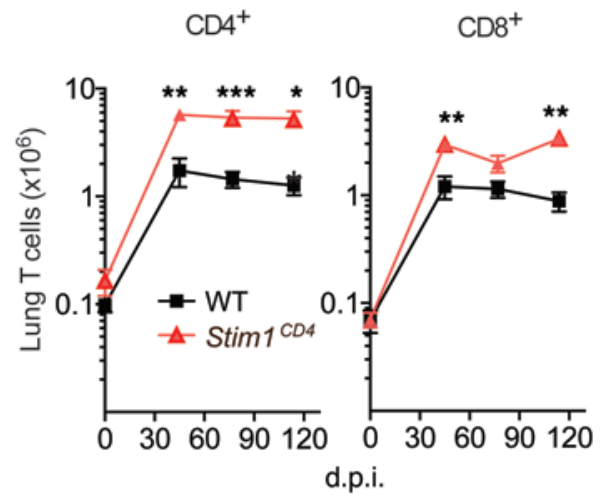

C

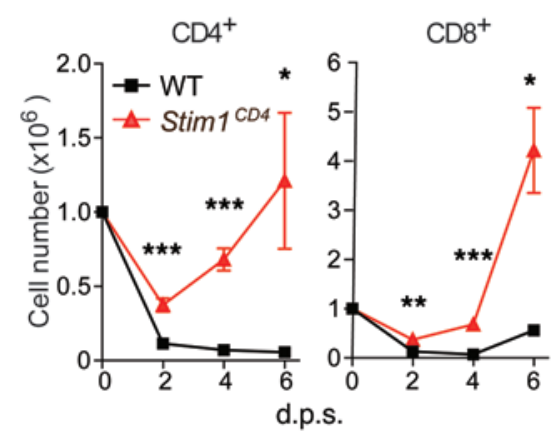

D

\section{Gated on $\mathrm{CD}^{+}{ }^{+} \mathrm{T}$ cells}

E

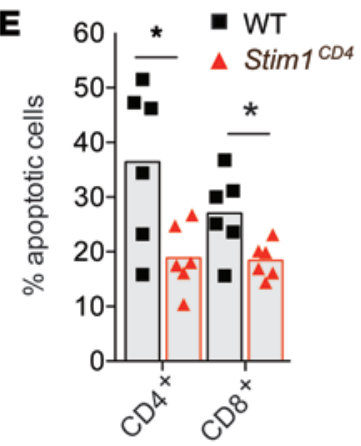

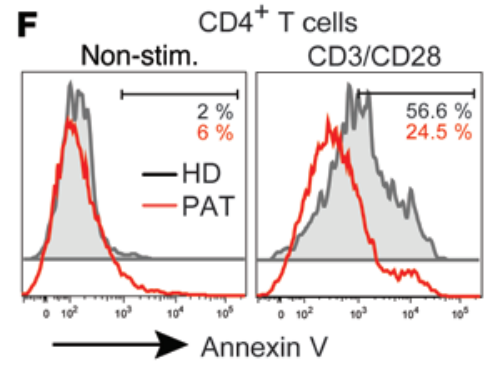

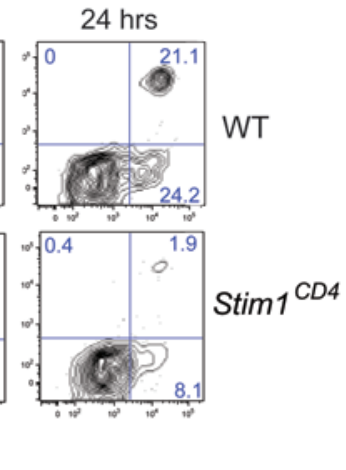

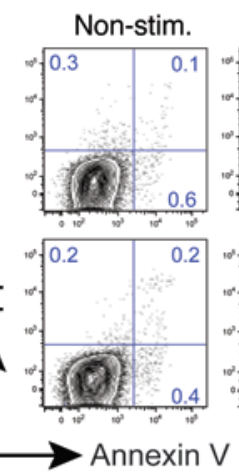
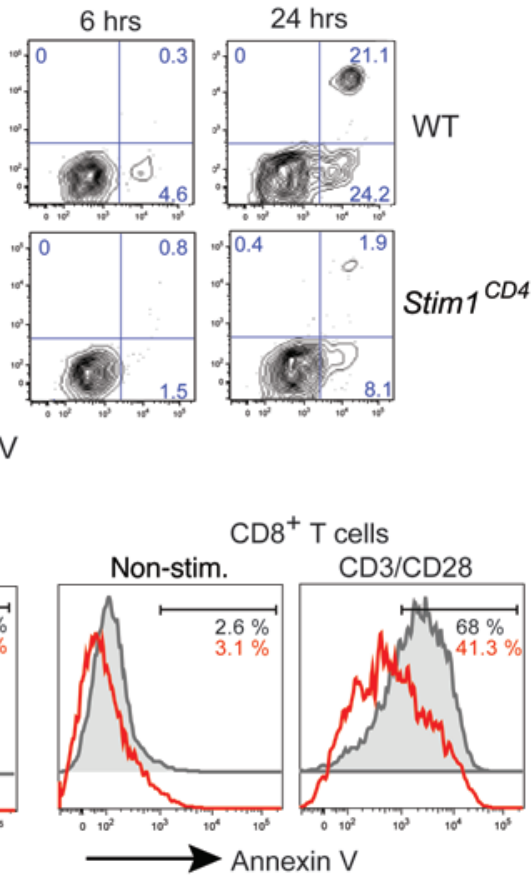

Figure 3. STIM1 controls AICD of T cells during chronic infection. (A) Infiltration of T cells into the lungs of WT and Stim7 $7^{\mathrm{CD} 4}$ mice at $114 \mathrm{~d}$.p.i. with Mtb. T cells were stained with $\alpha \mathrm{CD} 3$ antibody (red); images are representative of 5 mice per group. Original magnification, $\times 400$. Arrows indicate inflammatory infiltrates with T cell accumulation. (B) Absolute numbers of $\mathrm{CD} 4^{+}$and $\mathrm{CD} 8^{+} \mathrm{T}$ cells in lungs of WT and Stim ${ }^{\mathrm{CD} 4}$ mice determined by flow cytometry. Line graphs show mean \pm SEM for 4 to 5 mice per group and time point. (C) Absolute numbers of in vitro-expanded splenic CD4 ${ }^{+}$and CD8 $8^{+} T$ cells from uninfected WT and Stim $7^{\mathrm{CD} 4}$ mice after a second stimulation with $2 \mu \mathrm{g} / \mathrm{ml} \alpha \mathrm{CD} 3$. Line graphs show mean \pm SEM for 3 mice per group and time point. d.p.s., days post stimulation. (D and E) Apoptosis of in vitro-expanded CD4 ${ }^{+}$T cells isolated from spleens of uninfected WT and Stim $7^{\mathrm{CD} 4}$ mice and restimulated with $\alpha \mathrm{CD} 3$ for 6 and 24 hours; cells were analyzed by flow cytometry for annexin $\mathrm{V}$ and PI. Representative contour plots (D) and frequencies (E) of annexin $\mathrm{V}^{+}$apoptotic CD4+ and $C D 8^{+} T$ cells 24 hours after restimulation with $\alpha$ CD3. Each dot represents 1 mouse from 2 independent experiments with 3 mice per group. (F) Apoptosis in primary T cells from the peripheral blood of a HD and a SOCE-deficient PAT with ORAl1 p.R91W mutation (10) after restimulation for 16 hours with $\alpha$ CD3/ $\alpha C D 28$-coated beads. Histograms of annexin $V$ staining are representative of 2 independent experiments. Statistical significance in B-E was calculated by Student's $t$ test. ${ }^{*} P<0.05 ;{ }^{*} P<0.01 ;{ }^{* * *} P<0.001$.

altered response is not limited to mouse $\mathrm{T}$ cells, as we also found enhanced IFN- $\gamma$ production by $\mathrm{CD}^{+}$and $\mathrm{CD} 8^{+} \mathrm{T}$ cells from the ORAI1-deficient PAT in response to IL-12p70/IL-18 stimulation (Figure $5 \mathrm{~F}$ and Supplemental Figure 2B). As in STIM1deficient murine $\mathrm{T}$ cells, PMA/ionomycin stimulation failed to induce IFN- $\gamma$ expression in the PAT's T cells, consistent with the known role of the $\mathrm{Ca}^{2+} / \mathrm{NFAT}$ pathway in TCR-mediated IFN- $\gamma$ production (Figure 5F, Supplemental Figure 2B, and refs. 7, 4143). A strong correlation between IFN- $\gamma$ production and IL-12R $\beta 1$ / IL-12R $\beta 2$ expression in T cells has been shown in human TB (44), and NFAT was reported to silence IL-12R $\beta 2$ expression (45). We found that expression of IL-12R and IL-18R mRNA was in fact increased in T cells of the ORAI1-deficient PAT (Supplemental Figure 2C). Together, our results indicate that STIM1 and SOCE 
A

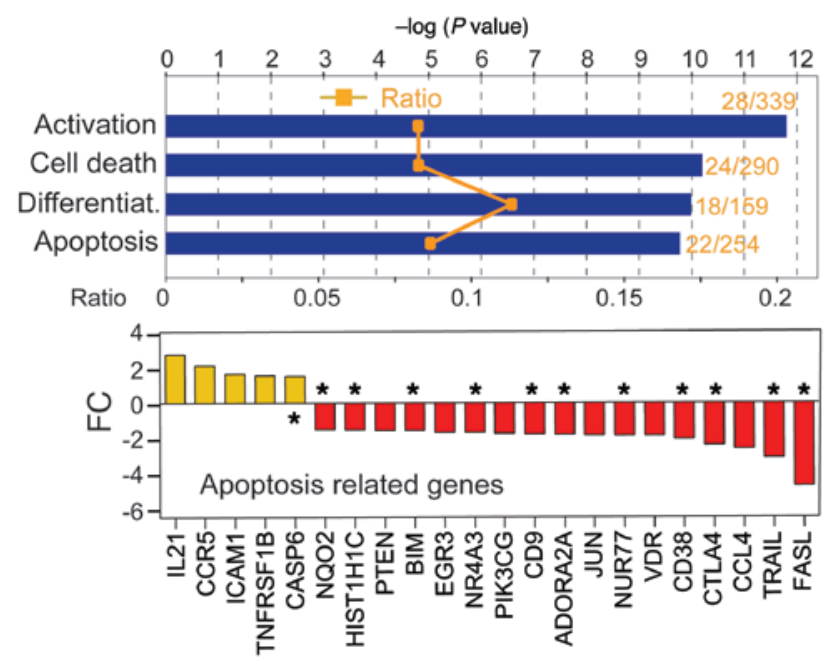

B

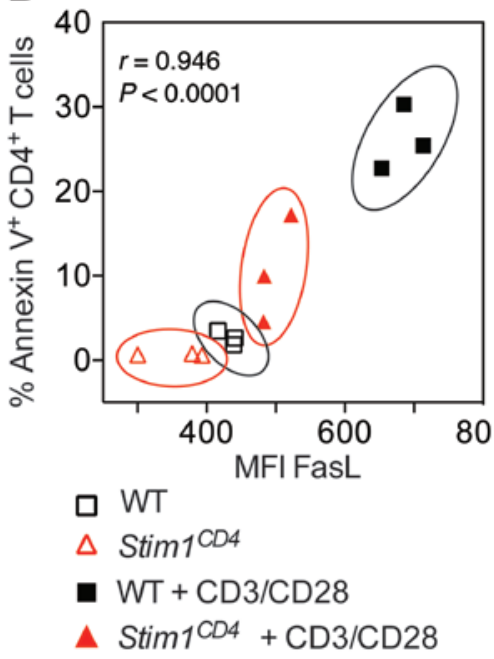

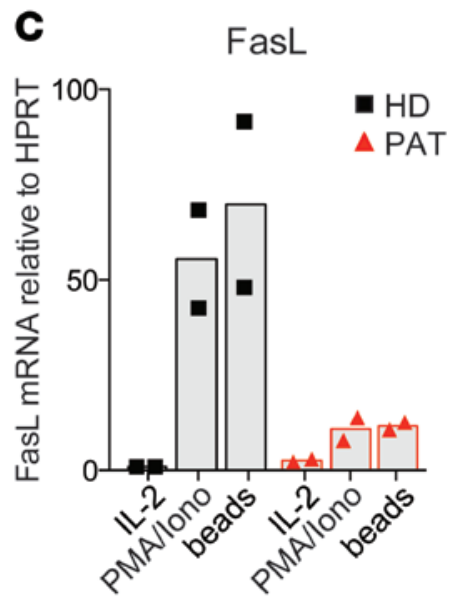

D

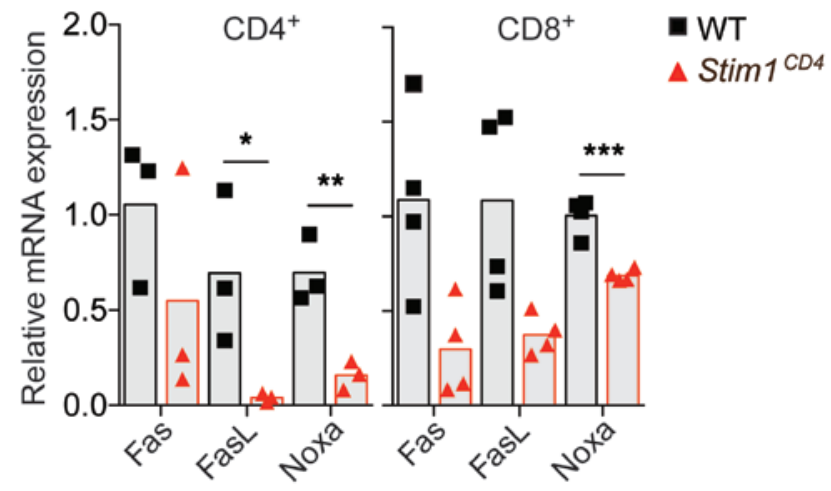

Figure 4. STIM1-dependent regulation of proapoptotic factors in T cells. (A) Microarray analysis of mRNA expression in CD4+ cells from the spleens of WT or $5 \operatorname{tim} 7^{\mathrm{CD} 4}$ mice (3 mice per group) stimulated for 48 hours with $\alpha \mathrm{CD} 3 / \alpha \mathrm{CD} 28$. Bar graphs show the results of a pathway analysis (IPA software) indicating the ratio of dysregulated genes per pathway (orange symbols, top panel), statistical significance (blue bars, top panel), and average fold changes (FC) in the expression of apoptosis-regulating factors (bottom panel; $P<0.05$ for all genes shown). Asterisks denote known proapoptotic factors in T cells. (B) Correlation of the mean fluorescence intensity (MFI) of FasL expression on splenic CD4+ $\mathrm{T}$ cells and frequency of annexin $\mathrm{V}^{+}$cells with or without restimulation with $2 \mu \mathrm{g} / \mathrm{ml} \alpha \mathrm{CD} 3$ for 16 hours. Correlation coefficient was calculated by Spearman's rho test. (C) FasL expression by primary T cells from the peripheral blood of an HD and a PAT with ORAl1 p.R91W mutation (PAT) (10) after restimulation of cells for 16 hours with PMA/ionomycin (P+I), IL-2, or $\alpha$ CD3/ $\alpha \mathrm{CD} 28$-coated beads. Bar graphs are representative of 2 independent experiments. (D) Transcript levels of proapoptotic factors Noxa, Fas, and FasL in lungs of WT and Stim $7^{C D 4}$ mice 77 days after Mtb infection, as determined by quantitative RT-PCR. Gene expression was normalized to Cd4 and Cd8 mRNA levels. Each dot represents 1 mouse. Statistical significance was calculated by Student's $t$ test. ${ }^{*} P<0.05 ;{ }^{* *} P<0.01 ;{ }^{* *} P<0.001$.

play important, albeit opposing, roles in TCR-mediated and cytokine-dependent production of IFN- $\gamma$ by T cells. Impaired activation of NFAT in STIM1-deficient T cells likely accounts for the initially ( $<60$ d.p.i.) reduced IFN- $\gamma$ levels in the lungs of Mtb-infected Stim $1^{\mathrm{CD} 4}$ mice but, as levels of myeloid cell-derived IL-12/IL-18 increase, STIM1-deficient T cells become hyperresponsive to cytokine stimulation and produce increased amounts of IFN- $\gamma$ in a TCR-independent manner.

Selective reduction in iTregs in STIM1-deficient mice during chronic Mtb infection. FOXP $3^{+}$Tregs play an important role in limiting immune responses and inflammation that arise during chronic infections $(29,30,46)$. In PATs with chronic hepatitis C virus (HCV) infection, frequencies of virus-specific $\mathrm{FOXP}^{+}$Tregs inversely correlate with markers of liver damage, suggesting that Tregs contain chronic inflammation and subsequent liver damage in HCV carriers $(47,48)$. Two subsets of FOXP3 ${ }^{+}$Tregs can be distinguished, natural Tregs (nTreg) and inducible Tregs (iTregs), both of which are important for maintaining immunological self tolerance and restraining potentially harmful immune responses (49). Whereas nTregs develop in the thymus, iTregs convert from naive $\mathrm{CD}^{+} \mathrm{T}$ cells in the periphery, for instance, during chronic inflammation (50). We observed a significantly reduced frequency of STIM1-deficient CD4 ${ }^{+} \mathrm{CD} 25^{+} \mathrm{FOXP3}{ }^{+}$Tregs in the lungs of $M t b$-infected mice compared with infected WT littermates at all stages of infection (Figure 6A). This is in contrast to uninfected $S t i m 1^{C D 4}$ mice that had numbers of pulmonary FOXP $3^{+}$Tregs sim- 
ilar to those of WT controls (Supplemental Figure 4A and ref. 32), indicating that STIM1 deficiency does not impair Treg development and/or homeostasis in uninfected mice. We hypothesized that, during $M t b$ infection, the lack of STIM1 might impair the expansion and/or homeostasis of nTregs or the differentiation of iTregs. nTregs can be distinguished from iTregs by the transcription factor Helios and the membrane coreceptor Neuropilin-1 (NRP-1) (51-53). Absolute Helios ${ }^{-}$NRP-1- iTreg numbers in the lungs of $M t b$-infected Stim $1^{C D 4}$ mice were significantly decreased only at 77 d.p.i., and Helios ${ }^{+} \mathrm{NRP}-1^{+}$nTreg numbers were moderately increased compared with those of control mice due to pulmonary lymphocytosis (Supplemental Figure 4B). Importantly, the frequencies of pulmonary nTregs were similar in $M t b$-infected WT and Stim $1^{C D 4}$ mice (Figure 6B), consistent with normal numbers of thymic nTregs in uninfected Stim $1^{C D 4}$ mice (32). In contrast, the frequencies of pulmonary iTregs were significantly reduced in $M t b$-infected Stim $1^{C D 4}$ mice at 77 d.p.i. and 114 d.p.i. compared with WT controls (Figure 6B). Accordingly, the ratio of iTreg to effector T cells in the lungs of STIM1-deficient mice was significantly lower than in WT mice (Supplemental Figure 4C).

IFN- $\gamma$ has been shown to negatively regulate iTreg differentiation in vitro (54). The frequencies of iTregs in the lungs of $M t b$-infected Stim1 $1^{C D 4}$ mice correlated negatively with pulmonary IFN- $\gamma$ concentrations over the course of infection (Figure 6C), suggesting that increased IFN- $\gamma$ levels in STIM1-deficient mice suppress iTreg differentiation. Indeed, we found that both IL-12 and IFN- $\gamma$ significantly $(P<0.05$ for IL-12; $P<0.001$ for IFN- $\gamma$ ) compromised the differentiation of naive $\mathrm{CD} 4^{+} \mathrm{T}$ cells into $\mathrm{FOXP3}^{+}$iTregs in vitro. Instead, both cytokines shifted the polarization of $\mathrm{CD} 4^{+} \mathrm{T}$ cells to IFN- $\gamma$-producing effector $\mathrm{T}$ cells despite the presence of TGF- $\beta$ (Figure 6D and Supplemental Figure 5, A and B). IL-12 and IFN- $\gamma$ not only prevented the de novo differentiation of iTregs, but also reduced the frequencies of established FOXP3 ${ }^{+}$iTregs, possibly by interfering with the maintenance or lineage commitment of iTregs (Figure 6E and Supplemental Figure 5C). Together, these results indicate that excessive IFN- $\gamma$ and IL-12 levels in the lungs of $M t b$-infected Stim $1^{C D 4}$ mice contribute to reduced frequencies of iTregs and thereby exacerbate pulmonary inflammation.

STIM1 has a $C D 4^{+} T$ cell-intrinsic role in the development of iTregs. The role of STIM1 in iTreg development is not known, and we hypothesized that STIM1 might play an additional CD $4^{+}$ $\mathrm{T}$ cell-intrinsic role, independent of the extrinsic effects of IFN- $\gamma / \mathrm{IL}-12$. We found that the frequency of FOXP3 ${ }^{+}$iTregs was significantly reduced in the absence of STIM1 compared with WT control when we differentiated naive $\mathrm{CD} 4^{+} \mathrm{T}$ cells in the presence of TGF- $\beta$ for 3 days in vitro (Figure 7A). This role of SOCE is not specific to murine iTregs because $\mathrm{CD} 4^{+} \mathrm{T}$ cells of the ORAI1-deficient PAT also failed to develop into FOXP3 ${ }^{+}$Helios $^{-}$ iTregs after TCR/TGF- $\beta$ stimulation in vitro (Figure 7B). A global comparison of mRNA expression profiles in murine iTregs differentiated in vitro from naive WT, and STIM1-deficient CD $4^{+}$ $\mathrm{T}$ cells revealed a significant deregulation of over 100 genes that belong to an iTreg signature (Figure 7C). Among genes up- or downregulated in the absence of STIM1 are several molecules previously linked to iTreg function and differentiation, such as FOXP3, ITGAE (CD103), SGK-1, SATB-1, and IL-3 (Figure 7D).
To investigate whether STIM1 also plays a role in the differentiation of iTregs in vivo, we adoptively transferred naive CD4 ${ }^{+}$ $\mathrm{T}$ cells from WT or Stim $1^{C D 4}$ mice to lymphopenic Rag1 $^{-/-}$mice, a commonly used model to study iTreg conversion in vivo (50). We found markedly reduced frequencies of $\mathrm{FOXP}^{+}$iTregs in the spleens of $\mathrm{Rag1}^{-/-}$mice that had received STIM1-deficient compared with WT CD $4^{+}$T cells (Figure 7E) despite comparable frequencies of total $\mathrm{CD} 4^{+} \mathrm{T}$ cells (data not shown). Reduced iTreg numbers in the absence of STIM1 were due to impaired differentiation, but not maintenance, of iTregs because tamoxifeninduced genetic deletion of Stim1 in iTregs after their development in vitro or in vivo did not affect their frequency compared with WT controls (Figure 7, F-H, and data not shown). We also found that STIM1 is not required for the suppressive function of iTregs because in vitro-differentiated WT and STIM1-deficient iTregs were equally able to suppress $\mathrm{T}$ cell proliferation and IL-12p40 production by macrophages (Supplemental Figure 6, A and $\mathrm{B})$. Together, our findings reveal a $\mathrm{CD} 4^{+} \mathrm{T}$ cell-intrinsic role of STIM1 and SOCE in the development of iTregs that is likely to contribute to immunoregulation and prevention of excessive inflammation during chronic $M t b$ infection.

\section{Discussion}

We show here that STIM1 and SOCE play multiple roles in adaptive immunity to chronic infection by controlling important regulatory mechanisms of the $\mathrm{T}$ cell-mediated immune response. STIM1 is thus critical to limiting the injurious pulmonary inflammation that is associated with chronic $M t b$ infection (see schematic in Figure 8).

During acute $M t b$ infection, STIM1 is required for optimal IFN- $\gamma$ production by $\mathrm{T}$ cells, which is consistent with in vitro $(32,38,55)$ and acute viral infection (3) models. Although IFN- $\gamma$ levels were reduced in Stim $1^{C D 4}$ mice early in infection, lung bacterial loads were surprisingly not increased concomitantly, as one would expect given the important role of IFN- $\gamma$ in immunity to $\mathrm{TB}(20,21)$. Control of $M t b$ growth in $\operatorname{Stim}^{\mathrm{CD} 4}$ mice during acute infection was likely due to residual IFN- $\gamma$ production by STIM1deficient $\mathrm{T}$ cells, consistent with the phenotype we observed in $M t b$-infected heterozygous Ifng ${ }^{+/-}$mice. In these mice, the frequency of IFN- $\gamma$-producing T cells was reduced by $50 \%$, but lung bacterial burdens at 35 d.p.i. were similar to those in WT mice. In contrast, homozygous If $\mathrm{ng}^{-/-}$mice have 10-fold increased bacterial burdens at this time, indicating that IFN- $\gamma$ in Stim $1^{C D 4}$ mice and $I \mathrm{fng}^{+/-}$is produced in excess of what is needed to control acute $M t b$ infection. However, we cannot rule out that the initial defect in IFN- $\gamma$ production by STIM1-deficient $\mathrm{T}$ cells contributed to increased bacterial growth at later stages of infection, a delay that could be explained by the slow growth of $M t b$ in vivo.

During chronic infection with $M t b$, STIM1 takes on multiple immune regulatory roles to prevent pulmonary hyperinflammation and tissue damage. First, STIM1 mediates contraction of the pool of activated T cells following repeated TCR stimulation by regulating the expression of proapoptotic molecules. In our mouse model of pulmonary $M t b$ infection, a reduction in the frequency of IFN- $\gamma$-producing $\mathrm{T}$ cells in the lungs was shown to occur 5 to 6 weeks after infection (56). In the absence of STIM1, however, $\mathrm{CD}^{+}$and $\mathrm{CD}^{+} \mathrm{T}$ cells expand dramatically at as early 
A
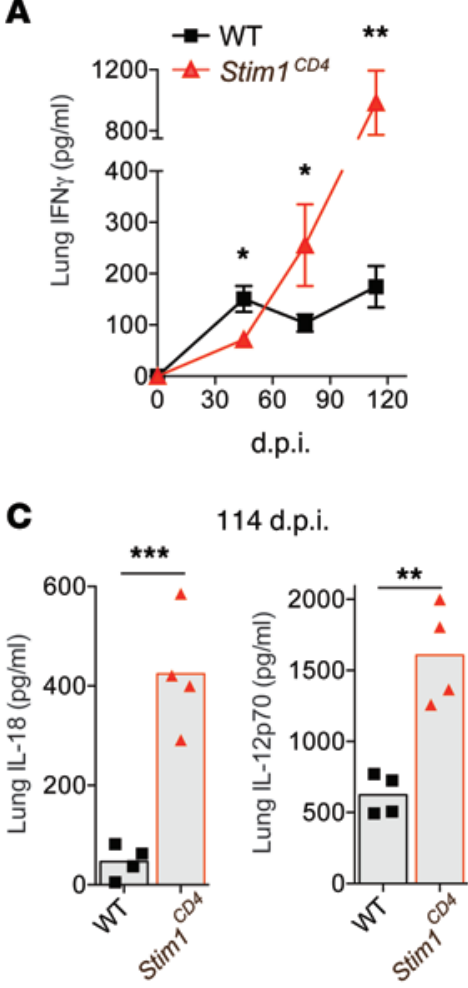

B
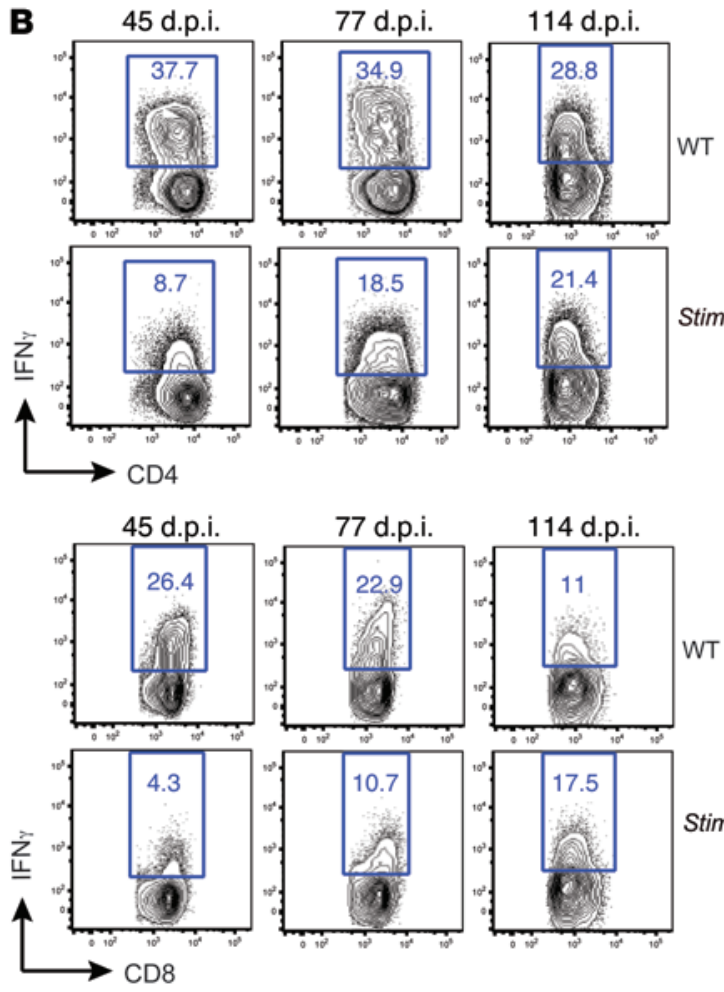

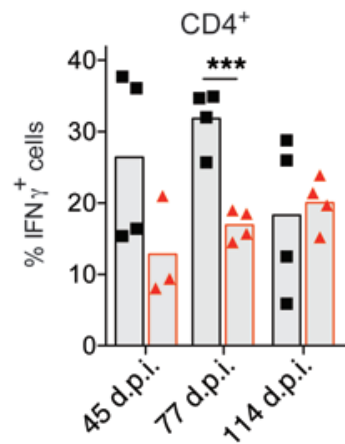

- WT

$\Delta$ Stim $1^{\mathrm{CD}}$
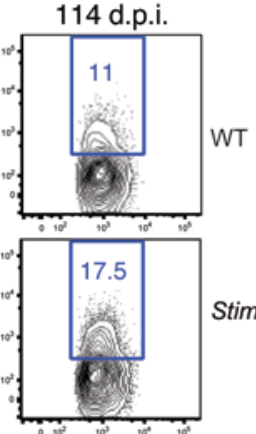
$\mathrm{CD}^{+}$

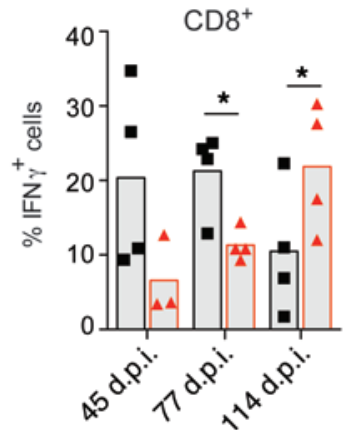

- WT a Stim $1^{\mathrm{CO} 4}$

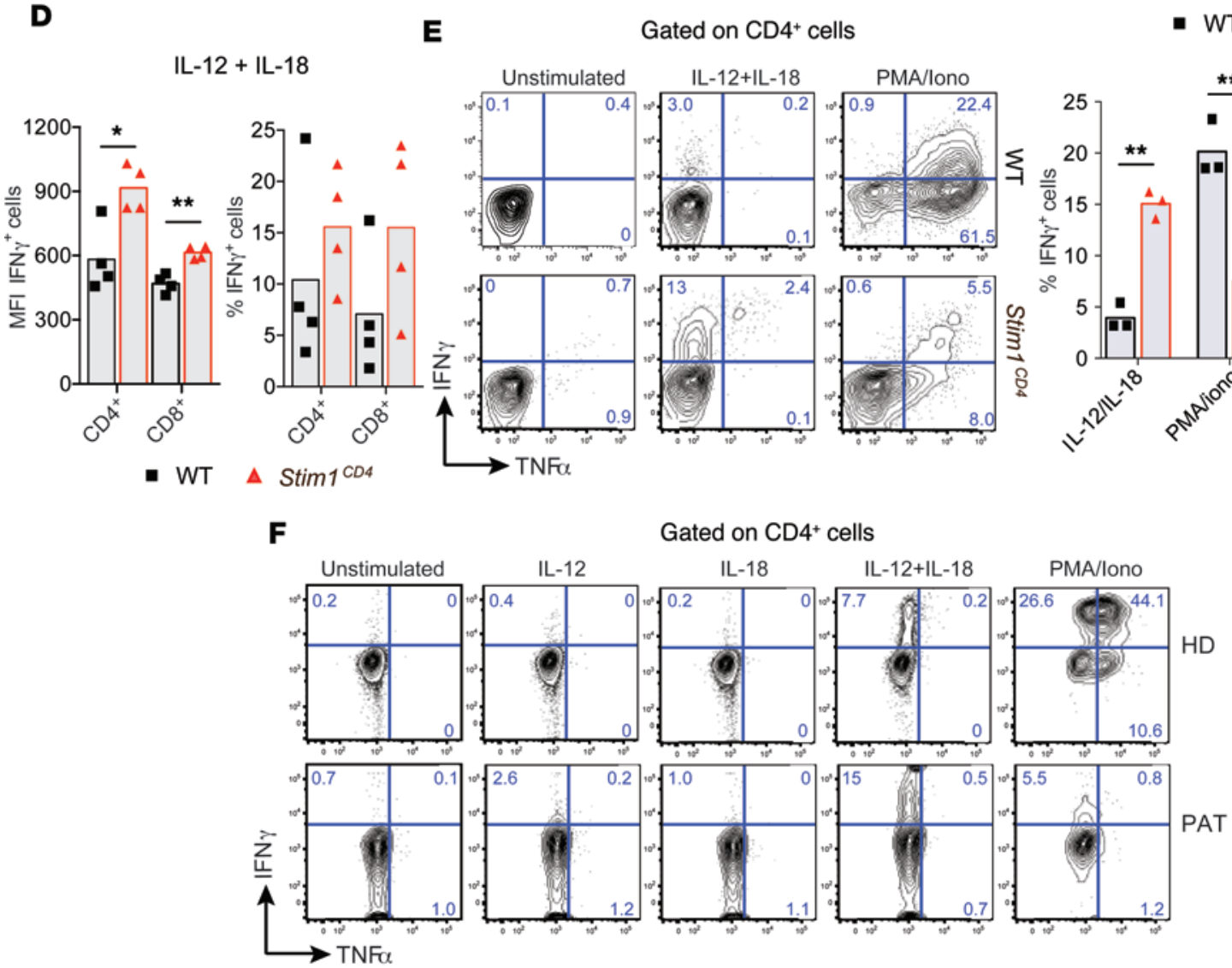


Figure 5. STIM1 is required for IFN- $\gamma$ production during acute but not chronic Mtb infection. (A) IFN- $\gamma$ in supernatants of lung homogenates from $M t b$-infected WT and Stim $7^{C D 4}$ mice measured by ELISA. Line graphs show mean \pm SEM for 5 mice per group and time points. (B) Frequencies of IFN- $\gamma^{+} \mathrm{CD}^{+}$and $\mathrm{CD} 8^{+} \mathrm{T}$ cells from the lungs of WT or Stim $1^{\mathrm{CD} 4}$ mice at indicated time points p.i.; cells were restimulated ex vivo with PMA/ionomycin for 6 hours. Representative contour plots (left) and frequencies of IFN- $\gamma^{+}$T cells (each dot represents 1 mouse). (C) IL-12p70 and IL-18 in supernatants of lung homogenates of WT or Stim $7^{\mathrm{CD} 4}$ mice measured by ELISA at 114 d.p.i. (D) IFN- $\gamma$ production by lung T cells of Mtb-infected WT and Stim $7^{\mathrm{CD} 4}$ mice isolated at 114 d.p.i. and restimulated ex vivo with recombinant IL-12 and IL-18 for 6 hours. Shown are MFI and frequencies of IFN- $\gamma^{+}$cells. Each dot represents 1 mouse. (E) Splenic CD4+ T cells from noninfected WT or Stim $7^{C D 4}$ mice were stimulated with $\alpha C D 3 / \alpha C D 28$ for 6 days in vitro and restimulated with IL-12/IL-18 or PMA/ionomycin for 6 hours. Representative contour plots (left) and frequencies of IFN- $\gamma^{+}$and TNF- $\alpha^{+}$T cells (right; each dot represents 1 mouse). (F) IFN- $\gamma$ and TNF- $\alpha$ production by PBL from a PAT with ORAl1 p.R91W mutation (PAT) (10) and cord blood cells from a HD after stimulation with recombinant IL-12, IL-18, IL-12/IL-18, or PMA/ionomycin for 6 hours. Shown are representative contour plots of CD4+ $T$ cells from 2 independent experiments (for corresponding CD8 ${ }^{+} T$ cell data, see Supplemental Figure 2B). Statistical significance was calculated by Student's $t$ test. ${ }^{*} P<0.05 ;{ }^{* *} P<0.01 ;{ }^{* *} P<0.001$.

as 45 d.p.i. due to continuous antigen exposure and impaired AICD. Second, although STIM1-deficient T cells initially show defective TCR-dependent IFN- $\gamma$ expression during acute $M t b$ infection, production of IFN- $\gamma$ becomes independent of STIM1 during chronic TB, and high levels of IFN- $\gamma$ are detectable in the lungs of Stim ${ }^{C D 4}$ mice beyond 100 d.p.i. While impaired AICD and increased responsiveness to IL-12/IL-18 in the absence of STIM1 are $\mathrm{T}$ cell-intrinsic defects, increased numbers of myeloid cells and approximately 40 -fold higher lung bacterial burdens create an inflammatory milieu that contributes extrinsically to a positive feedback loop amplifying IL-12/IL-18 secretion, thereby fueling excessive IFN- $\gamma$ production, pulmonary inflammation, and bacterial replication. Third, STIM1 controls the frequency of iTregs in the lungs of infected mice in both $\mathrm{T}$ cell-intrinsic and -extrinsic manners. STIM1 is required for the expression of FOXP3 in naive $\mathrm{CD}^{+}{ }^{+} \mathrm{T}$ cells and therefore their conversion into iTregs. In addition, increased IFN- $\gamma$ and IL-12 levels in the lungs of $M t b$-infected mice further suppress iTreg differentiation and maintenance $(54,57)$. Thus, in the absence of STIM1, low frequencies of iTregs may fail to control the proliferation and function of effector $\mathrm{T}$ cells, and potentially myeloid cells, in the lungs of $M t b$-infected mice. Together these immunomodulatory defects in the absence of SOCE in T cells contribute to pulmonary hyperinflammation and, eventually, to the early mortality of $M t b$-infected Stim $1^{C D 4}$ mice.

STIM1 is essential to controlling AICD in T cells, and its deletion results in expansion of $\mathrm{T}$ cells in the lungs of $M t b$-infected mice. This function of STIM1 is consistent with the known role of $\mathrm{Ca}^{2+}$-dependent transcription factors of the NFAT family in regulating FasL expression. Stimulation of human Jurkat $\mathrm{T}$ cells by $\mathrm{CD} 3$ crosslinking or ionomycin mediates binding of NFAT to the FASLG enhancer region, resulting in FasL expression (58). Using murine $\mathrm{T}$ cells, Kim et al. observed that retroviral overexpression of constitutively active NFAT1 increases apoptosis in T cells, even under resting conditions (34). In contrast, NFAT1deficient and, even more pronouncedly, NFAT1/NFAT4 doubledeficient, lymphocytes are hyperproliferative and have elevated primary and secondary immune responses $(43,59-61)$. This is at least partially caused by impaired lymphocyte apoptosis due to reduced FasL expression upon activation $(62,63)$. Fas/FasLmediated apoptosis plays an important role in controlling $M t b$ infection. Mtb-infected Lpr (Fas) mutant mice showed significantly increased lung bacterial burdens compared with WT mice during chronic (40-120 d.p.i.) but not acute infection (64). This is similar to our observations in $M t b$-infected Stim $1^{C D 4}$ mice and suggests that SOCE-dependent expression of FasL and apoptosis are required to control chronic $M t b$ infection. Several other proapoptotic factors expressed at lower levels in STIM1-deficient T cells were shown to be regulated by the $\mathrm{Ca}^{2+} /$ calcineurin/NFAT pathway, including TRAIL (65), CD38 (66), and NUR77 (67). CD38induced activation of $\mathrm{T}$ cells triggers $\mathrm{Ca}^{2+}$ influx and apoptosis in human $\mathrm{T}$ cells, which was inhibited by cyclosporin A (which inhibits calcineurin and NFAT activation), suggesting that CD38 mediates its proapoptotic function by regulating $\mathrm{Ca}^{2+}$ signaling (66). Expression of the steroid receptor NUR77 is regulated by $\mathrm{Ca}^{2+}$ following TCR stimulation and promotes thymocyte apoptosis by activating the transcription factor myocyte enhancer factor 2 (MEF2), which binds to the Nur77 promoter (67). Taken together, our data indicate that SOCE regulates several $\mathrm{Ca}^{2+}$-signaling pathways to control expression of proapoptotic factors, thereby limiting proliferation of effector $\mathrm{T}$ cells during chronic infection.

As a second important immunoregulatory mechanism, STIM1 controls differentiation of $\mathrm{CD}_{4}^{+} \mathrm{T}$ cells into $\mathrm{FOXP}^{+}$iTregs in both cell-extrinsic and cell-intrinsic manners, which accounts for the reduced frequencies of FOXP3 ${ }^{+}$Helios ${ }^{-N R P}-1^{-}$iTregs, but not of FOXP3 ${ }^{+} \mathrm{Helios}^{+} \mathrm{NRP}-1^{+}$nTregs, in the lungs of chronically $M t b$-infected Stim $1^{\mathrm{CD} 4}$ mice. IFN- $\gamma$ and IL-12 negatively regulate conversion of naive $\mathrm{CD} 4^{+} \mathrm{T}$ cells into iTregs and instead shift the differentiation of $\mathrm{CD}^{+} \mathrm{T}$ cells toward $\mathrm{Th} 1$ cells, consistent with previous studies $(54,57)$. This inhibitory effect of IFN- $\gamma$ on iTreg differentiation is also observed in vivo, as IFN- $\gamma$-deficient mice have elevated numbers of $\mathrm{FOXP3}^{+}$iTregs (but not nTregs) compared with WT mice (54). In addition, we found that STIM1 and SOCE play a $\mathrm{CD}^{+} \mathrm{T}$ cell-intrinsic role in the differentiation of iTregs. The conversion of naive $\mathrm{CD} 4^{+} \mathrm{T}$ cells into iTregs in vitro and in vivo was impaired in the absence of STIM1. In contrast, STIM1 was not required for the maintenance or lineage commitment of iTregs, as inducible deletion of Stim1 after iTreg differentiation in vitro or in vivo did not alter the frequencies of FOXP3 ${ }^{+}$iTregs.

Our gene-expression analysis showed that STIM1 regulates expression of more than 100 iTreg signature genes, including Foxp3. This is in line with recent studies showing that members of the $\mathrm{Ca}^{2+}$-dependent NFAT transcription factor family regulate FOXP3 expression in iTregs $(68,69)$. NFAT binds, together with SMAD2 $/ 3$, directly to the conserved noncoding sequence 1 in the Foxp 3 locus and regulates FOXP3 expression in response to TCR stimulation and TGF- $\beta$ (68-70). In addition to Foxp3, expression of other genes associated with iTregs was significantly deregulated in STIM1-deficient T cells. These include Itgae (Cd103) and $I l 3$, which are also controlled by NFAT $(68,71)$. In contrast to reduced iTreg differentiation, nTreg numbers were normal in 
A $\quad 77$ d.p.i.

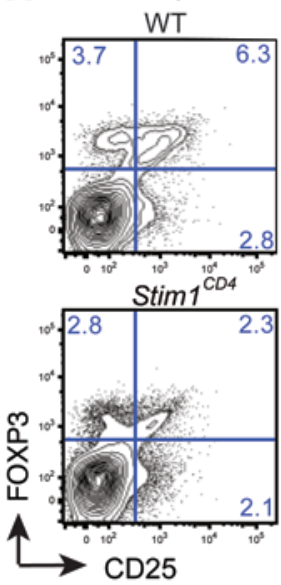

B $\quad 77$ d.p.i.

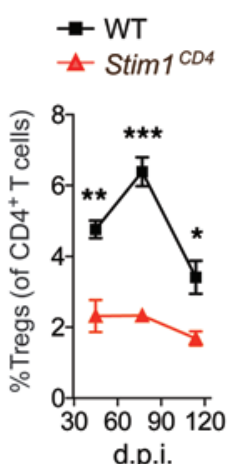

d.p.i.

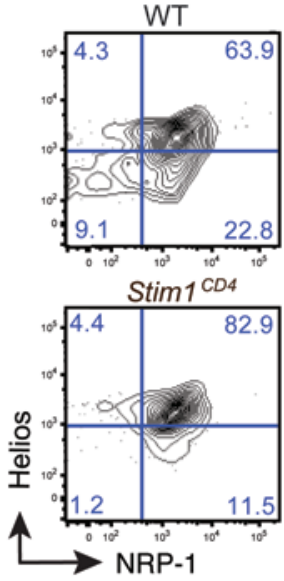

NRP-1
Helios ${ }^{+}$NRP-1 ${ }^{+}$Helios- NRP-1-
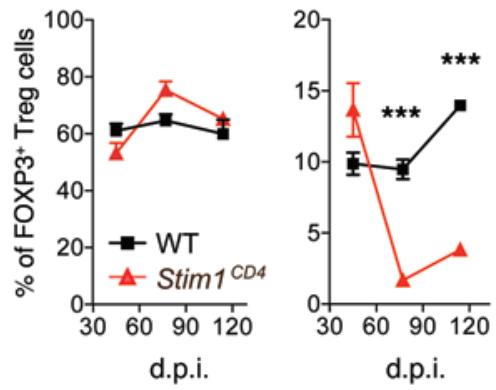

C

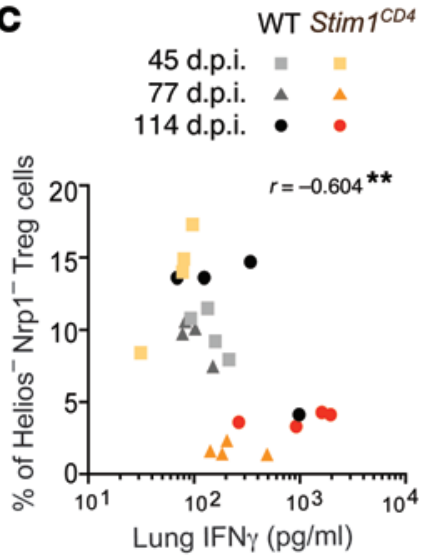

D

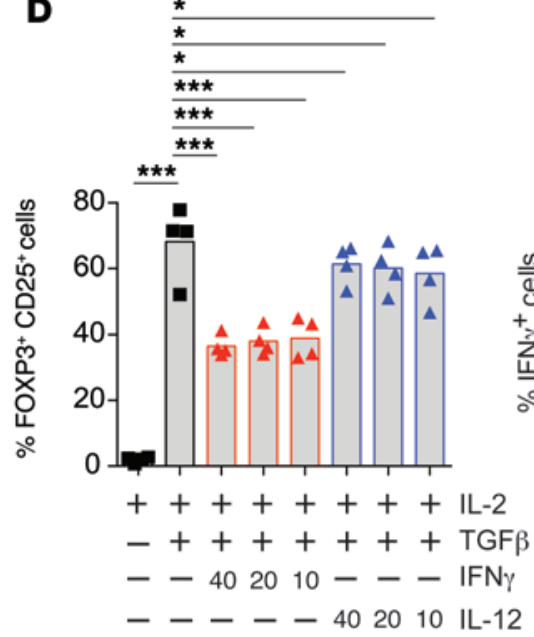

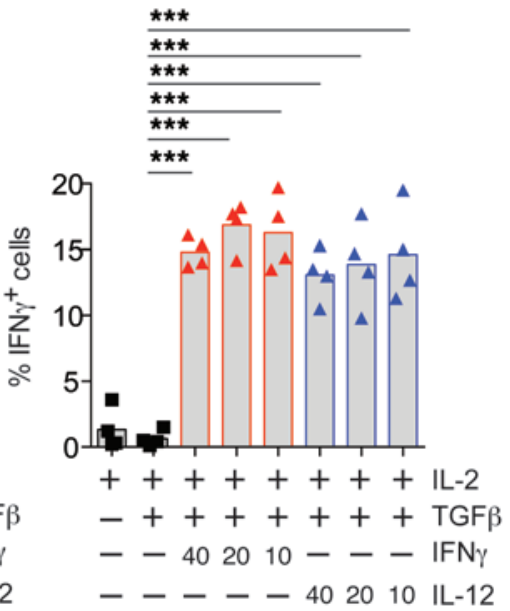

E $\mathrm{IFN} \gamma$ IL-12

$\mathrm{IFN} \gamma+\mathrm{IL}-12$

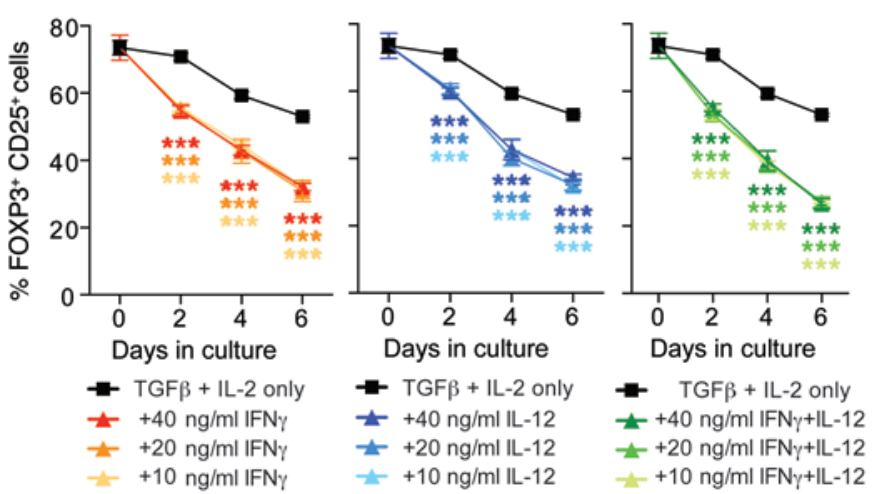

Figure 6. Lack of STIM1 results in reduced iTreg numbers in chronic Mtb infection. (A) CD4+CD25+FOXP3+ Tregs in lungs of Mtb-infected WT or Stim $7^{\mathrm{CD} 4}$ mice at 77 d.p.i. Representative contour plots (left) and frequencies (mean \pm SEM, right) of Tregs from 4 to 5 mice per group and time point. (B) Helios and NRP-1 expression by CD4+CD25+FOXP3+ Tregs in the lungs of mice at 77 d.p.i. Frequencies (line graphs) of Helios ${ }^{+}$NRP-1+ ${ }^{+}$Tregs and Helios ${ }^{-N R P-1-}$ iTregs over the course of Mtb infection are the mean \pm SEM of 4 to 5 mice per group and time point. (C) Correlation of pulmonary IFN- $\gamma$ levels and frequencies of iTregs in the lung of $M t b$-infected WT and Stim $7^{\mathrm{CDA}}$ mice. (D) Effects of IFN- $\gamma$ and IL-12 on iTreg differentiation in vitro. Naive CD4 ${ }^{+} \mathrm{T}$ cells from WT mice were stimulated with $\alpha \mathrm{CD} 3 / \alpha \mathrm{CD} 28$ and IL-2/TCF- $\beta$ in the presence of the indicated concentrations (in ng/ml) of IFN- $\gamma$ and IL-12 for 3 days in vitro. Bar graphs show frequencies of CD25+FOXP3 $3^{+}$iTregs (left) and IFN- $\gamma$-producing T cells after restimulation with PMA/ionomycin for 6 hours (right) as determined by flow cytometry. (E) Effects of IFN- $\gamma$ and IL-12 on the stability of iTregs. WT CD4 ${ }^{+}$T cells were differentiated into iTregs as described in $\mathbf{D}$ and incubated with IFN- $\gamma$, IL-12, or IFN- $\gamma$ plus IL-12 for another 6 days. The frequencies of CD25+FOXP3 ${ }^{+}$cells were determined by flow cytometry. Data in $\mathbf{D}$ and $\mathbf{E}$ represent the mean \pm SEM of 4 mice per group. Statistical significance was calculated by Student's $t$ test. ${ }^{*} P<0.05$; ${ }^{* *} P<0.01 ;{ }^{* * *} P<0.001$. 
A

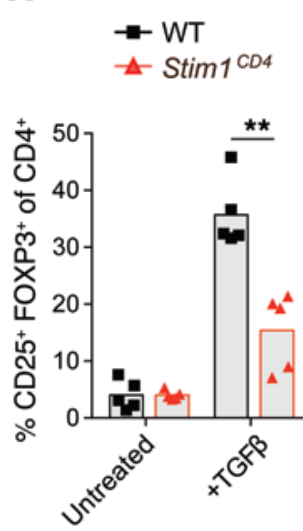

D
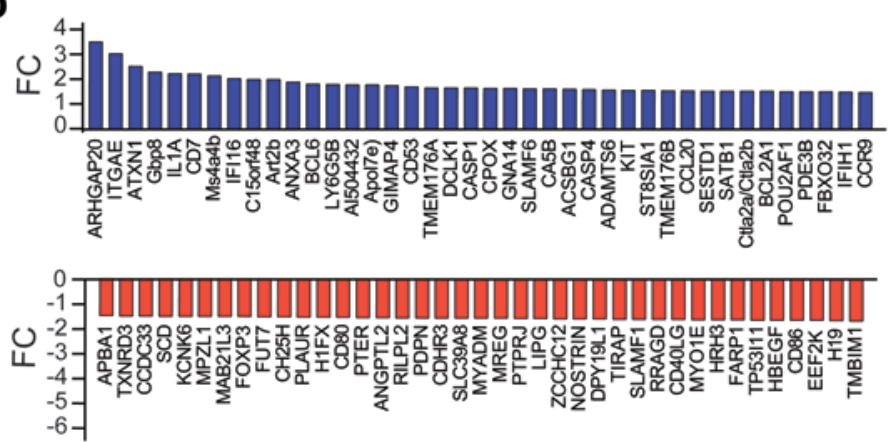

B
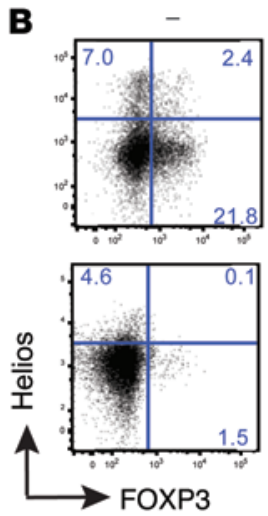

FOXP3
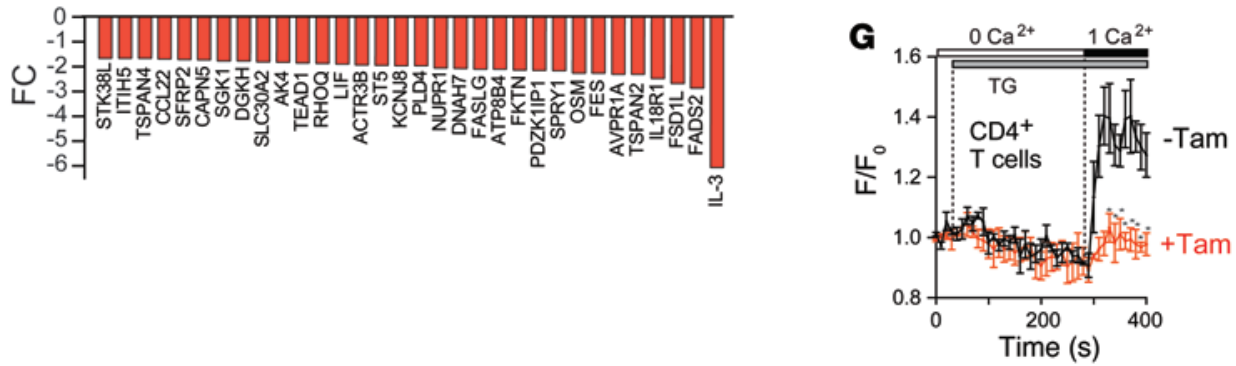

E

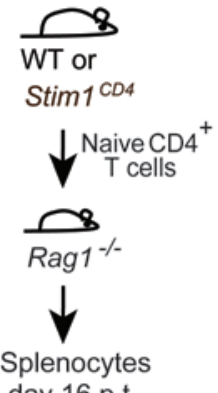

day 16 p.t.
C

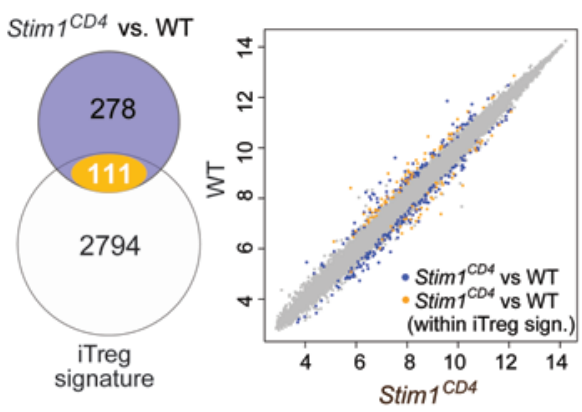

$\mathbf{F}$

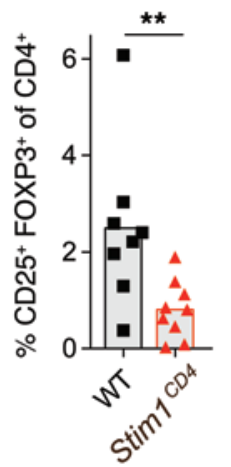

$\frac{2}{\text { Stim } 1 f(I / f)}$ UBC-ERT2-Cre $\downarrow_{\text {T cells }}^{\text {Naive }{ }^{+}}$ $\frac{2}{\operatorname{Rag} 1^{-/}}$ $\downarrow$ 8 weeks +/- Tam. i.p. $\downarrow 2$ weeks Isolate $\mathrm{mLN}$

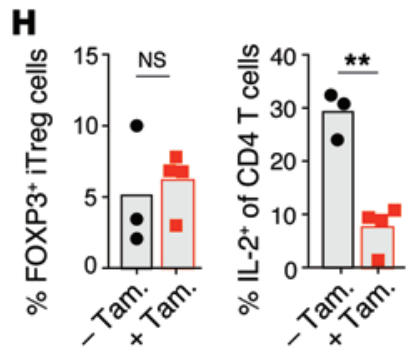

Figure 7. STIM1 regulates the development, but not the stability, of iTregs. (A) Frequencies of $C D 25^{+} F O X P 3^{+}$iTregs after in vitro $\alpha C D 3 / \alpha C D 28$ stimulation of naive splenic CD4+ T cells from WT or Stim ${ }^{104}$ mice with or without TCF- $\beta$ (untreated) for 3 days. (B) iTreg differentiation of human CD4 ${ }^{+}$T cells from a HD or PAT with ORAl1 p.R91W mutation (PAT) (10) after $\alpha$ CD3/ $\alpha$ CD28 stimulation with or without TGF- $\beta$ for 5 days in vitro. Flow cytometry dot plots showing Helios and FOXP3 expression are representative of 3 independent experiments. (C and D) Microarray analysis of WT versus Stim $7^{\mathrm{CD} 4}$ iTregs. (C) Venn diagram (left) showing more than 100 iTreg signature genes (see Methods) differentially regulated in Stim ${ }^{\mathrm{CD} 4} \mathrm{~T}$ cells. Scatter plot (right) of robust multi-array average (RMA) expression of genes that are part (orange) or not part (blue) of the iTreg signature. (D) Bar graphs representing fold changes of iTreg genes in Stim ${ }^{\mathrm{CD} 4}$ cells $\left(P<0.05\right.$ for genes shown). (E) Frequencies of splenic Tregs 16 days after adoptive transfer of naive CD4 ${ }^{+}$ T cells from WT or Stim $7^{C D 4}$ mice. Each symbol represents 1 mouse; data are from 2 independent experiments. (F-H) Unimpaired iTreg maintenance after inducible deletion of Stim1 in vivo. (F) Experimental design (see Methods). (C) SOCE in adoptively transferred CD4 ${ }^{+} \mathrm{T}$ cells from mesenteric lymph nodes of mice injected (+Tam) or not (-Tam) with tamoxifen. Mean Fluo-4 fluorescence $(F)$ over baseline $\left(F_{0}\right)( \pm S E M)$ measured by flow cytometry; data are representative of 3-4 mice per group. (H) Frequencies of FOXP3 ${ }^{+}$iTregs (left) and IL-2+CD4+ ${ }^{+}$cells (after PMA/ionomycin stimulation for 6 hours; right) isolated from mesenteric lymph nodes of recipient mice. Statistical significance calculated by Student's $t$ test. ${ }^{*} P<0.05$; ${ }^{* *} P<0.01$; ${ }^{* * *} P<0.001$.

uninfected and chronically $M t b$-infected STIM1-deficient mice, suggesting that STIM1 is more important for the development of iTregs than nTregs. Interestingly, complete deletion of SOCE in $\mathrm{T}$ cells from STIM1/STIM2 double-deficient mice $(32,72)$ or human PATs with mutations in STIM1 and ORAI1 genes $(11,73)$ (S. Feske, unpublished observations) also impairs nTreg development, resulting in reduced numbers of $\mathrm{FOXP3}^{+}$Tregs. Further emphasizing the importance of SOCE in iTreg differentiation, $\mathrm{T}$ cells from NFAT1/NFAT2, and NFAT1/NFAT4 double-deficient mice are unable to differentiate into iTregs, whereas nTreg development and function are normal $(68,74)$. These findings suggest that the lymphoproliferative phenotype observed in Stim $1^{C D 4}$ mice chronically infected with $M t b$ is caused by impaired iTreg differentiation rather than defective nTreg development $(38,75$, 76). Although differentiation of $\mathrm{FOXP3}^{+}$iTregs was defective in STIM1-deficient mice, their suppressive function in vitro was intact, which is consistent with unimpaired suppressive function of Tregs of a PAT with loss-of-function STIM1 mutation (73). 


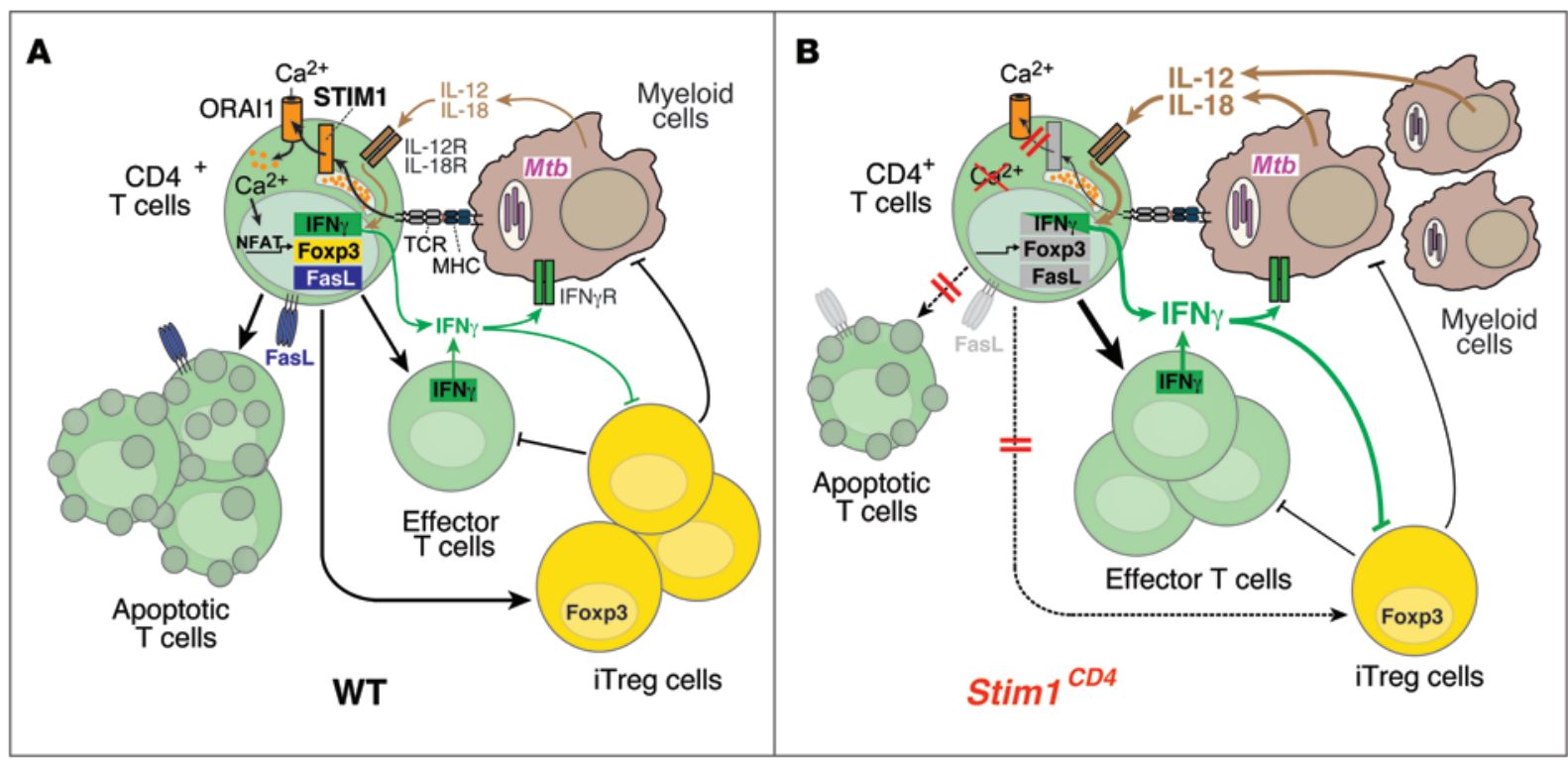

Figure 8. The role of STIM1 in chronic Mtb infection. (A) In WT mice, Mtb-infected macrophages/DCs present mycobacterial antigens via MHC class II to $\mathrm{CD4}^{+} \mathrm{T}$ cells, resulting in STIM1 activation, its binding to ORAl1, and $\mathrm{Ca}^{2+}$ influx (SOCE). SOCE activates NFAT and other Ca ${ }^{2+}$-dependent transcription factors, which regulate Fasl, Foxp3, and Ifng gene expression. FasL mediates AICD in T cells following repeated TCR stimulation, thereby preventing lymphoproliferation in chronic infection. FOXP3 expression is required for the differentiation of iTregs that suppress effector T cells and potentially myeloid cells. IFN- $\gamma$ production after TCR, but not IL-12/IL-18, stimulation is dependent on STIM1/SOCE. IFN- $\gamma$ secreted by effector T cells helps to contain Mtb infection and to recruit myeloid cells. (B) In STIM1-deficient mice, ORAl1 activation and SOCE are impaired, resulting in reduced expression of Fasl, Foxp3, and Ifng and other genes. Impaired AICD results in accumulation of effector T cells in Mtb-infected mice. Despite impaired TCR-dependent IFN- $\gamma$ production, STIM1-deficient T cells respond to IL-12/IL-18 and secrete more IFN- $\gamma$ during chronic Mtb infection, promoting the recruitment of myeloid cells that can be infected with $M t b$. Higher bacterial burdens result in increased secretion of IL-12/IL-18 and perpetuation of pulmonary inflammation. Secretion of IFN- $\gamma$ by T cells and IL-12 by myeloid cells inhibits differentiation of iTregs, adding to the STIM1-dependent, T cell-intrinsic defect in iTreg development. Together, these defects result in pulmonary hyperinflammation/consolidation, loss of respiratory function, and premature death of Stim $7^{\mathrm{CDA}}$ mice.

Similar observations were made in NFAT2-deficient $\mathrm{CD} 4^{+} \mathrm{T}$ cells, which fail to efficiently differentiate into $\mathrm{FOXP}^{+}$iTregs, while the remaining iTregs were functional (68). Together, our data indicate that STIM1-mediated $\mathrm{Ca}^{2+}$ signaling is essential for the conversion of naive $\mathrm{CD} 4^{+} \mathrm{T}$ cells into iTregs, but that it is largely dispensable for their stability and suppressive functions.

iTregs are essential to regulate the homeostasis of pro- and anti-inflammatory immune responses during infections (50). In $M t b$ infection, Tregs have been studied for their role in delaying the onset and limiting the efficiency of adaptive immune responses (31). Early during $M t b$ infection, pathogen-specific nTregs were shown to proliferate in lung-draining lymph nodes, where they suppress priming of effector $\mathrm{T}$ cells and promote bacterial dissemination. The role of iTregs in controlling inflammation during chronic $M t b$ infection is largely unknown. Interestingly, BCGinduced iTregs ameliorate chronic inflammation in a mouse model of atopic dermatitis (77). Our data of reduced iTreg frequencies in $M t b$-infected Stim $1^{C D 4}$ mice indicate that STIM1 controls immune homeostasis and prevents pulmonary hyperinflammation.

The complex role of STIM1 in Mtb infection is further emphasized by its biphasic and opposing control of IFN- $\gamma$ expression in the acute and chronic phases of infection. Although STIM1 is required forTCR-induced IFN- $\gamma$ production early in $M t b$ infection, it assumes a negative regulatory role in IL-12/IL-18-mediated IFN- $\gamma$ production during chronic infection. TCR stimulation results in activation of SOCE-regulated transcription factor
NFAT, which cooperates with STAT4 (in naive T cells) and T-bet (in committed Th1 cells) to promote transcription of Ifng $(42,78)$. NFAT and T-bet bind to a highly conserved distal enhancer in the Ifng locus and synergize to enhance IF $\mathrm{N}-\gamma$ expression (79). T cells from NFAT1- or NFAT1/NFAT4-deficient mice have impaired IFN- $\gamma$ production $(41,43,63)$, suggesting that NFAT1 and NFAT4 promote Th1 cell differentiation. Since SOCE is required to activate NFAT, impaired IFN- $\gamma$ expression in STIM1-deficient mice following TCR stimulation can be explained by defective NFAT function. In contrast, TCR-independent mechanisms of IFN- $\gamma$ production in activated T cells, mediated by IL-12/IL-18, become important during chronic $M t b$ infection. IL-12 binds to the heterodimeric IL-12R, which consists of the constitutively expressed $\beta 1$ chain and the inducible $\beta 2$ chain. The IL-12R $\beta 2$ promoter contains a NFATc2-binding site that functions as a silencer of IL-12R $\beta 2$ expression, and preventing NFAT activation with cyclosporin $\mathrm{A}-$ an inhibitor of the $\mathrm{Ca}^{2+}$-dependent phosphatase calcineurin that activates NFAT - results in increased IL-12R $\beta 2$ levels on T cells (45). Negative regulation of IL-12R $\beta 2$ by calcineurin/NFAT is consistent with increased responsiveness of STIM1-deficient $\mathrm{CD} 4^{+}$and $\mathrm{CD} 8^{+} \mathrm{T}$ cells to IL-12/IL-18 stimulation and probably contributes to elevated IFN- $\gamma$ levels in the lungs of chronically $M t b$-infected Stim $1^{C D 4}$ mice. The proinflammatory milieu in the lungs of these mice is likely to activate other lymphoid cells, including NK cells, NKT cells, and innate lymphoid cells (ILC), to produce IFN- $\gamma$. 
The initially reduced and later increased IFN- $\gamma$ expression in STIM1-deficient mice reinforces the ambiguous role of IFN- $\gamma$ in TB. Although IFN- $\gamma$ is essential for controlling $M t b(20,21)$, several lines of evidence indicate that IFN- $\gamma$ levels do not ultimately correlate with protection in humans, and some studies even show positive correlation with lung disease (reviewed in ref. 80). We found that, during acute $M t b$ infection, lower IFN- $\gamma$ levels in Stim $1^{C D 4}$ and Ifng $g^{+/-}$ mice do not correlate with higher mycobacterial burdens in the lungs. But during chronic infection, high levels of IFN- $\gamma$ in Stim1 $1^{C D 4}$ mice fail to limit bacterial growth and, on the contrary, are associated with pulmonary hyperinflammation, including increased recruitment of infectable myeloid cells. Similar observations were made in LCMV-infected mice, suggesting that IFN- $\gamma$ is involved in the recruitment of macrophages to the site of infection (81). Continued production of IFN- $\gamma$ by STIM1-deficient T cells may therefore exacerbate chronic infection with $M t b$ by promoting accumulation of myeloid cells in the lungs, thereby increasing the pool of cells that can be infected by $M t b$ and the overall pulmonary mycobacterial burden. Enhanced IFN- $\gamma$ expression by STIM1-deficient T cells in response to $M t b$ is somewhat reminiscent of the immune reconstitution inflammatory syndrome (IRIS) in HIV-infected PATs who develop an exacerbated immune response to pathogens, including $M t b$, with IFN- $\gamma$ production and inflammation after initiation of antiretroviral therapy and recovery of $\mathrm{T}$ cell numbers (82). The role of STIM1 and SOCE in the regulation of T cell-mediated immunity likely extends beyond TB to other chronic infections in which IFN- $\gamma$ serves as an important regulator of the immune response, including infections with hepatitis $\mathrm{B}$ and $\mathrm{C}$ viruses, herpes simplex virus (HSV), or Helicobacter pylori (83). Our findings in STIM1-deficient mice illuminate the ambiguous role of IFN- $\gamma$ in chronic infections and may therefore have important therapeutic consequences for the assessment of IFN- $\gamma$ modulators, including potential vaccines that rely on the production of IFN- $\gamma$ for protection.

Taken together, our results shed light on the importance of $\mathrm{Ca}^{2+}$ signaling in $\mathrm{T}$ cell-mediated immune regulation and inflammation during chronic infection. They offer an explanation for the complex immunodeficiency observed in human PATs with CRAC channelopathy, who frequently suffer from chronic viral and mycobacterial infections and lymphoproliferative diseases. As $\mathrm{Ca}^{2+}$ signaling modulators are being developed for the treatment of autoimmune diseases, inflammation, and allergy $(1,84)$, our results underline the importance of assessing their effects on highly prevalent, chronic infections.

\section{Methods}

Mice. WT C57BL/6 mice, B6.SJL-Ptprc ${ }^{a} P e p c^{b} /$ BoyJ (CD45.1) mice, and Rag1 $^{-/-}$mice were purchased from The Jackson Laboratory. Stim ${ }^{\mathrm{CD} 4}$ mice were described previously (32). Mice with inducible deletion of the Stim1 gene (Stim1 $\left.{ }^{1 / f l} U B C-E R^{T 2}-C r e\right)$ were generated by crossing Stim $1^{f / f l}$ mice with B6.Cg-Tg(UBC-Cre/ERT2)1Ejb/J (UBC-ER ${ }^{T 2}$-Cre) mice (The Jackson Laboratory). Ifng ${ }^{+/}$mice were generated by crossing Ifng ${ }^{-}$mice (The Jackson Laboratory) with C57BL/6 mice. For infections with $M t b$, mice were housed under barrier conditions in the ABSL3 facility at New York University Langone Medical Center (NYULMC). For tissue harvesting, mice were euthanized by $\mathrm{CO}_{2}$ asphyxiation, followed by cervical dislocation. All mice were between 8 and 12 weeks of age at the beginning of the experiment.
Bacterial infection. Mtb laboratory strain $\mathrm{H} 37 \mathrm{Rv}$ was grown as previously described (85). Mice were infected via the aerosol route, using an inhalation exposure system (Glas-Col) (86) calibrated to deliver approximately $100 \mathrm{CFU} /$ mouse. The infectious dose was confirmed on day 1 by plating whole-lung homogenates from 5 mice on Middlebrook $7 \mathrm{H} 11$ agar. $\mathrm{CFU}$ were counted after incubation at $37^{\circ} \mathrm{C}$ for 2 to 3 weeks. To determine bacterial burdens throughout the infection, serial dilutions of lung homogenates were plated on Middlebrook 7H11 agar.

Histology and immunohistochemistry. The left lungs of mice were harvested and processed as previously described (87) for histopathological examination, immunohistochemical staining, using polyclonal antibodies specific for CD68 (FA-11, AbD Serotec) and CD3e (2GV6, Ventana), and image analysis (see below).

Image analysis. Open source image-processing software ImageJ (http://rsbweb.nih.gov/ij/) was used for quantitation of alveolar spaces in the lungs and of specific immunohistochemical staining. Analysis was performed according to the directions of the ImageJ User Guide for sizing particles.

ELISA and multiplex assays. Supernatants from whole-lung homogenates harvested at various time points following $M t b$ infection were analyzed by ELISA for detection of IFN- $\gamma$ (BD Biosciences), IL12p40, IL-12p70, and IL-18 (eBioscience) and by multiplex assay for GM-CSF, M-CSF, IL-1 $\beta$, IL-12p70, IL-18, MCP-1/CCL2, MIP1 $\alpha / C C L 3$, and RANTES/CCL5 (EMD Millipore).

Quantitative real-time PCR and microarray analysis. Total RNA was extracted from the left lungs of mice using TRIzol reagent (Invitrogen) and converted into cDNA as previously described (85). The cDNA equivalent of $50 \mathrm{ng}$ of total RNA was analyzed for specific gene expression in triplicate for each sample by quantitative realtime PCR using Platinum SYBR Green qPCR SuperMix (Invitrogen) and an Opticon 2 thermocycler (Bio-Rad). Sequences of primers used for PCR can be found in Supplemental Table 1. Thermal cycling conditions were $95^{\circ} \mathrm{C}$ for 10 minutes followed by 40 cycles at $94^{\circ} \mathrm{C}$ for 45 seconds, $58^{\circ} \mathrm{C}$ for 30 seconds, and $72^{\circ} \mathrm{C}$ for 30 seconds. For quantitation, relative $\mathrm{Ct}$ values were determined by normalization to $C d 4, C d 8$, or housekeeping gene $H r p t$ cDNA expression using the $\Delta \Delta \mathrm{Ct}$ method. For microarray analysis, $\mathrm{CD} 4^{+} \mathrm{T}$ cells from WT or Stim $1^{C D 4}$ mice were isolated and stimulated with functional grade $\alpha \mathrm{CD} 3 \varepsilon$ and $\alpha \mathrm{CD} 28$ (145-2C11 and 37.51, BioXCell) antibodies for 48 hours in the presence or absence of $5 \mathrm{ng} / \mathrm{ml} \mathrm{TGF}-\beta$ (Peprotech) (iTreg skewing conditions). Total RNA was isolated using RNeasy Micro kit (QIAGEN). Biotin-labeled amplified aRNA was hybridized to 1.0 Eon expression chips (Affymetrix) according to the manufacturer's protocols. The values in the sample data tables were derived from the Expression Console Software (Affymetrix) by performing a gene-level normalization and signal summarization on the raw CEL files (gene-level analysis). Obtained CHP files were subsequently analyzed and visualized using TAC software (Affymetrix) and IPA pathway analysis software (QIAGEN). Three age-matched mice per group and condition were used; no technical replicates were used. To determine the iTreg signature, gene-expression levels in WT CD $4^{+} \mathrm{T}$ cells cultured under iTreg polarizing conditions were compared with those in WT CD $4^{+} \mathrm{T}$ cells cultured under nonpolarizing (Th0) conditions (no TGF- $\beta$ ). Genes were included in the iTreg signature when their expression was 1.5 -fold above or below mRNA levels in ThO cells and differences were statistically significant $(P<0.05$ by ANOVA using TAC software). Primary microarray data 
from Figures 4 and 7 were deposited in the NCBI's Gene Expression Omnibus (GEO GS66933).

Flow cytometry. For analysis of immune cell populations, mouse lungs were processed for flow cytometry as previously described (86). The following anti-murine fluorophore-conjugated antibodies were used for staining: CD4 (RM4-5, BioLegend), CD8 $\alpha$ (53-6.7, BD Biosciences), CD11c (HL3, BD Biosciences), CD11b (M1/70, BD Biosciences), Gr-1 (RB6-8C5, BD Biosciences), FasL (MFL3, eBioscience), Fas (15A7, eBioscience), IFN- $\gamma$ (XMG1.2, BioLegend), TNF- $\alpha$ (MP6-XT22, BioLegend), CD62L (MEL-14, BD Biosciences), CD44 (IM7, BioLegend), CD25 (PC61, BD Biosciences), FOXP3 (FJK-16s, eBioscience), Helios (22F6, BioLegend), and NRP-1 (biotinylated goat polyclonal antibody, catalog BAF566, R\&D Systems) followed by fluorophore-conjugated streptavidin (eBioscience). For analysis of human $\mathrm{T}$ cells, the following fluorophore-conjugated antibodies were used for flow cytometry: CD4 (OKT4, BioLegend), CD8a (HIT8a, BioLegend), IFN- $\gamma$ (4S.B3, BioLegend), TNF- $\alpha$ (MAb11, BioLegend), Helios (22F6, BioLegend), and FOXP3 (259D, BioLegend). For apoptotic cell staining, fluorophore-conjugated annexin $\mathrm{V}$ probe (BD Biosciences) and propidium iodide (PI) (BD Biosciences) were used. Samples were acquired on an LSRII flow cytometer using FACSDiva software (BD Biosciences) and further analyzed using FlowJo software (Tree Star).

Invitromurine Tcellassays. $\mathrm{WTCD} 4^{+}$and $\mathrm{CD} 8^{+}$Tcellswereisolated from spleen or mesenteric lymph nodes of mice using negative selection kits (STEMCELL Technologies) and stimulated with $0.5 \mu \mathrm{g} / \mathrm{ml}$ plate-bound $\alpha \mathrm{CD} 3$ and $1 \mu \mathrm{g} / \mathrm{ml} \alpha \mathrm{CD} 28$ antibodies (BioXCell). After 48 hours, RPMI 1640 medium was supplemented with $20 \mathrm{U} / \mathrm{ml}$ recombinant human IL-2 (NIH/AIDS reagent program). After 7 days, cell numbers and frequency of apoptotic cells were determined by flow cytometry after annexin $\mathrm{V}$ and PI staining. For restimulation experiments, $\mathrm{CD} 4^{+}$and $\mathrm{CD}^{+} \mathrm{T}$ cells were incubated with $2 \mu \mathrm{g} / \mathrm{ml}$ $\alpha \mathrm{CD} 3$ for 6,16 , or 24 hours. For cytokine production, cells were stimulated with $1 \mu \mathrm{M}$ ionomycin plus $20 \mathrm{nM}$ PMA or $20 \mathrm{ng} / \mathrm{ml} \mathrm{IL}-12$ and $200 \mathrm{ng} / \mathrm{ml} \mathrm{IL-18}$ for 6 hours in the presence of Brefeldin A. IFN- $\gamma$ production was determined by intracellular cytokine staining and flow cytometry as described above. For iTreg differentiation experiments, naive $\mathrm{CD} 4{ }^{+} \mathrm{CD} 62 \mathrm{~L}^{+} \mathrm{CD} 25^{-} \mathrm{T}$ cells were isolated from $\mathrm{WT}$ and Stim $1^{C D 4}$ mice and stimulated invitro with $\alpha \mathrm{CD} 3 / \alpha \mathrm{CD} 28$ and $2.5 \mathrm{ng} / \mathrm{ml}$ TGF- $\beta$. For some experiments, naive WT $\mathrm{CD} 4^{+} \mathrm{T}$ cells isolated from the spleen were stimulated with $\alpha \mathrm{CD} 3 / \alpha \mathrm{CD} 28$ and cultured in $20 \mathrm{U} / \mathrm{ml}$ recombinant human IL-2 and $5 \mathrm{ng} / \mathrm{ml}$ TGF- $\beta$ for 3 days in the presence or absence of recombinant murine IFN- $\gamma$ or IL-12 (10 to $40 \mathrm{ng} / \mathrm{ml}$; BD Biosciences). The frequency of FOXP3-expressing iTregs was determined by flow cytometry, and IF $\mathrm{N}-\gamma$ production was assessed by intracellular cytokine staining after stimulation of cells with PMA/ionomycin. To test the effects of exogenous IFN- $\gamma$ / IL-12 on the maintenance of in vitro-differentiated iTregs, naive $\mathrm{CD}^{+} \mathrm{T}$ cells from WT mice were cultured for 3 days as described above and subsequently incubated with IFN- $\gamma$, IL-12, or IFN- $\gamma /$ IL-12 for another 6 days. The frequency of $\mathrm{FOXP}^{+}$cells was determined by flow cytometry.

Tcelltransferexperiments. Naive $\mathrm{CD} 4^{+} \mathrm{CD} 45 \mathrm{RB}^{+} \mathrm{CD} 25^{-} \mathrm{T}$ cellswere isolated from the spleens of WT, Stim $1^{C D 4}$, or Stim $1^{f / f l} U B C-E R^{T 2}-C r e$ mice using a negative isolation kit and a SONY iCyt cell sorter. $1 \times 10^{6}$ cells were adoptively transferred to lymphopenic recipient $\mathrm{Ragl}^{-/-}$mice by i.v. injection. To study in vivo differentiation of
iTregs, spleens were harvested 16 days post transfer (p.t.) of WT or Stim $1^{C D 4} \mathrm{~T}$ cells and the frequencies of $\mathrm{CD} 25^{+} \mathrm{FOXP} 3^{+}$iTregs were determined by flow cytometry. To examine the role of STIM1 in iTreg stability in vivo, mice transferred with Stim1 $1^{f / f l} U B C-E R^{T 2}-C r e$ T cells were injected i.p. daily for 5 days with $1 \mathrm{mg} / \mathrm{mouse} / \mathrm{d}$ tamoxifen (Sigma-Aldrich) or vehicle (corn oil plus $5 \%$ ethanol) alone, starting at 8 weeks p.t. Mesenteric lymph nodes were harvested 2 weeks after the beginning of tamoxifen injections, and the frequency of FOXP3 ${ }^{+}$iTregs was determined by flow cytometry.

In vitro human $T$ cell assays. Cord blood cells or peripheral blood lymphocytes (PBL) from healthy donors (HD) and PBL from a SOCEdeficient PAT with ORAI1 p.R91W mutation (10) were cultured as described previously (88). Briefly, $1 \times 10^{6}$ cord blood cells or PBL isolated by Ficoll gradient centrifugation were stimulated using $\alpha \mathrm{CD} 3 /$ $\alpha \mathrm{CD} 28$-coated magnetic beads (Invitrogen) and cultured in RPMI 1640 medium containing $10 \mathrm{ng} / \mathrm{ml} \mathrm{IL-2} \mathrm{for} 35$ days. For apoptosis experiments, $\mathrm{T}$ cells were reactivated with $\alpha \mathrm{CD} 3 / \alpha \mathrm{CD} 28$ beads and apoptosis was assessed 6 hours later by annexin $\mathrm{V}$ and PI stainings. For intracellular cytokine staining, $\mathrm{T}$ cells were stimulated for 16 hours with $20 \mathrm{ng} / \mathrm{ml} \mathrm{IL-12} \mathrm{(R \& D),} 200 \mathrm{ng} / \mathrm{ml} \mathrm{IL-18} \mathrm{(Peprotech),} \mathrm{IL-12}$ plus IL-18, or PMA plus ionomycin for 4 hours or left unstimulated. GolgiStop (BD) was added for 4 hours before staining. For differentiation of iTregs, $\mathrm{CD}^{+} \mathrm{T}$ cells from HD and PAT were stimulated with $\alpha \mathrm{CD} 3 / \alpha \mathrm{CD} 28$ beads in the presence or absence of TGF- $\beta(\mathrm{R} \& \mathrm{D})$ at the indicated concentrations.

Statistics. $P$ values were calculated using a 2-tailed, unpaired Student's $t$ test and Prism 6 (GraphPad Software). Error bars represent mean \pm SEM. $P<0.05$ was considered statistically significant. Statistical correlation analyses were performed using the Spearman's rho test. Unless otherwise stated, the data shown represent 3 to 5 biological replicates in 1 experiment.

Study approval. All animal experiments were conducted in accordance with protocols approved by the IACUC of New York University School of Medicine. For experiments using primary human cells, informed consent for the studies was obtained from the PATs in accordance with the Declaration of Helsinki and IRB approval of the New York University School of Medicine.

\section{Acknowledgments}

This work was funded by NIH grants AI097302 (to S. Feske), AI065303 to (D. Unutmaz), AI051242 and AI084041 (to J.D. Ernst), and postdoctoral fellowships by the National Multiple Sclerosis Society (to P. Shaw) and the Deutsche Forschungsgemeinschaft (DFG) (to C. Weidinger [We 5303/1-1] and M. Vaeth [VA 882/1-1])

Address correspondence to: Stefan Feske, Department of Pathology, New York University School of Medicine, 550 First Avenue, Smilow 316, New York, New York 10016, USA. Phone: 212.263.9066; E-mail: feskes01@nyumc.org.

Derya Unutmaz's present address is: The Jackson Laboratory for Genomic Medicine, Farmington, Connecticut, USA.

Carl Weidinger's present address is: Charité - University Medicine Berlin, Division of Gastroenterology, Rheumatology and Infection Medicine, Berlin, Germany. 
1. Feske S, Wulff H, Skolnik EY. Ion channels in innate and adaptive immunity. Annu Rev Immunol. 2015;33:291-353.

2. Feske S, Skolnik EY, Prakriya M. Ion channels and transporters in lymphocyte function and immunity. Nat Rev Immunol. 2012;12(7):532-547.

3. Shaw PJ, Weidinger C, Vaeth M, Luethy K, Kaech SM, Feske S. CD $4^{+}$and CD ${ }^{+}$T cell-dependent antiviral immunity requires STIM1 and STIM2. J Clin Invest. 2014;124(10):4549-4563.

4. Weidinger C, Shaw PJ, Feske S. STIM1 and STIM2-mediated $\mathrm{Ca}(2+)$ influx regulates antitumour immunity by CD8(+) T cells. EMBO Mol Med. 2013;5(9):1311-1321.

5. Feske S. CRAC channelopathies. Pflugers Arch. 2010;460(2):417-435.

6. Feske S. Immunodeficiency due to defects in store-operated calcium entry. Ann N Y Acad Sci. 2011;1238:74-90.

7. Feske S, et al. Severe combined immunodeficiency due to defective binding of the nuclear factor of activated $\mathrm{T}$ cells in T lymphocytes of two male siblings. Eur J Immunol. 1996;26(9):2119-2126.

8. Le Deist F, et al. A primary T-cell immunodeficiency associated with defective transmembrane calcium influx. Blood. 1995;85(4):1053-1062.

9. Partiseti M, Le Deist F, Hivroz C, Fischer A, Korn $\mathrm{H}$, Choquet D. The calcium current activated by T cell receptor and store depletion in human lymphocytes is absent in a primary immunodeficiency. J Biol Chem. 1994;269(51):32327-32335.

10. Feske $S$, et al. A mutation in Orai1 causes immune deficiency by abrogating CRAC channel function. Nature. 2006;441(7090):179-185.

11. Picard C, et al. STIM1 mutation associated with a syndrome of immunodeficiency and autoimmunity. N Engl J Med. 2009;360(19):1971-1980.

12. Byun $\mathrm{M}$, et al. Whole-exome sequencingbased discovery of STIM1 deficiency in a child with fatal classic Kaposi sarcoma. J Exp Med. 2010;207(11):2307-2312.

13. McCarl CA, et al. ORAI1 deficiency and lack of store-operated $\mathrm{Ca}^{2+}$ entry cause immunodeficiency, myopathy, and ectodermal dysplasia. J Allergy Clin Immunol. 2009;124(6):1311-1318.

14. Srivastava S, Ernst JD, Desvignes L. Beyond macrophages: the diversity of mononuclear cells in tuberculosis. Immunol Rev. 2014;262(1):179-192.

15. Wolf AJ, et al. Initiation of the adaptive immune response to Mycobacterium tuberculosis depends on antigen production in the local lymph node, not the lungs. J Exp Med. 2008;205(1):105-115.

16. Urdahl KB. Understanding and overcoming the barriers to $\mathrm{T}$ cell mediated immunity against tuberculosis. Semin Immunol. 2014;26(6):578-587.

17. Nunes-Alves C, Booty MG, Carpenter SM, Jayaraman P, Rothchild AC, Behar SM. In search of a new paradigm for protective immunity to TB. Nat Rev Microbiol. 2014;12(4):289-299.

18. Bold TD, Ernst JD. CD $4^{+}$T cell-dependent IFN- $\gamma$ production by $\mathrm{CD}^{+}$effector $\mathrm{T}$ cells in Mycobacterium tuberculosis infection. JImmunol. 2012;189(5):2530-2536.

19. Philips JA, Ernst JD. Tuberculosis pathogenesis and immunity. Annu Rev Pathol. 2012;7:353-384.

20. Cooper AM, Dalton DK, Stewart TA, Griffin JP, Russell DG, Orme IM. Disseminated tuberculosis in interferon $\gamma$ gene-disrupted mice. JExp Med.
1993;178(6):2243-2247.

21. Flynn JL, Chan J, Triebold KJ, Dalton DK, Stewart TA, Bloom BR. An essential role for interferon $\gamma$ in resistance to Mycobacterium tuberculosis infection. J Exp Med.1993;178(6):2249-2254.

22. Dupuis $S$, et al. Human interferon- $\gamma$-mediated immunity is a genetically controlled continuous trait that determines the outcome of mycobacterial invasion. Immunol Rev. 2000;178:129-137.

23. Swain SL, McKinstry KK, Strutt TM. Expanding roles for CD4(+) T cells in immunity to viruses. Nat Rev Immunol. 2012;12(2):136-148.

24. Dorhoi A, Kaufmann SH. Perspectives on host adaptation in response to Mycobacterium tuberculosis: Modulation of inflammation. Semin Immunol. 2014;26(6):533-542.

25. Barber DL, Mayer-Barber KD, Feng CG, Sharpe $\mathrm{AH}$, Sher A. CD4 T cells promote rather than control tuberculosis in the absence of PD-1-mediated inhibition. J Immunol. 2011;186(3):1598-1607.

26. Lenardo M, et al. Mature T lymphocyte apoptosis - immune regulation in a dynamic and unpredictable antigenic environment. Annu Rev Immunol.1999;17:221-253.

27. Kulinski JM, Tarakanova VL, Verbsky J. Regulation of antiviral CD8 T-cell responses. Crit Rev Immunol. 2013;33(6):477-488.

28. Murphy FJ, Hayes I, Cotter TG. Targeting inflammatory diseases via apoptotic mechanisms. Curr Opin Pharmacol. 2003;3(4):412-419.

29. Veiga-Parga T, Sehrawat S, Rouse BT. Role of regulatory $\mathrm{T}$ cells during virus infection. Immunol Rev. 2013;255(1):182-196.

30. Smigiel KS, Srivastava S, Stolley JM, Campbell DJ. Regulatory T-cell homeostasis: steady-state maintenance and modulation during inflammation. Immunol Rev. 2014;259(1):40-59.

31. Larson RP, Shafiani S, Urdahl KB. Foxp3(+) regulatory T cells in tuberculosis. Adv Expe Med Biology. 2013;783:165-180.

32. Oh-Hora M, et al. Dual functions for the endoplasmic reticulum calcium sensors STIM1 and STIM2 in T cell activation and tolerance. Nat Immunol. 2008;9(4):432-443.

33. Waite JC, et al. Interference with $\mathrm{Ca}(2+)$ release activated $\mathrm{Ca}(2+)(\mathrm{CRAC})$ channel function delays T-cell arrest in vivo. Eur J Immunol. 2013;43(12):3343-3354.

34. Kim KD, Srikanth S, Yee MK, Mock DC, Lawson GW, Gwack Y. ORAI1 deficiency impairs activated $\mathrm{T}$ cell death and enhances $\mathrm{T}$ cell survival. J Immunol. 2011;187(7):3620-3630.

35. Denis M, Gregg EO, Ghandirian E. Cytokine modulation of Mycobacterium tuberculosis growth in human macrophages. Int J Immunopharmacol. 1990;12(7):721-727.

36. Desvignes L, Wolf AJ, Ernst JD. Dynamic roles of Type I and Type II IFNs in early infection with Mycobacterium tuberculosis. Jimmunol. 2012;188(12):6205-6215.

37. Feske S, Draeger R, Peter HH, Eichmann K, Rao A. The duration of nuclear residence of NFAT determines the pattern of cytokine expression in human SCID T cells. J Immunol. 2000;165(1):297-305.

38. McCarl CA, et al. Store-operated $\mathrm{Ca}^{2+}$ entry through ORAI1 is critical for T cell-mediated autoimmunity and allograft rejection. JImmunol.
2010;185(10):5845-5858.

39. Okamura H, Kashiwamura S, Tsutsui H, Yoshimoto T, Nakanishi K. Regulation of interferongamma production by IL-12 and IL-18. Curr Opin Immunol. 1998;10(3):259-264.

40. Feng CG, et al. Maintenance of pulmonary Th1 effector function in chronic tuberculosis requires persistent IL-12 production. J Immunol. 2005;174(7):4185-4192.

41. Kiani A, et al. Regulation of interferon $-\gamma$ gene expression by nuclear factor of activated T cells. Blood. 2001;98(5):1480-1488.

42. Macian F. NFAT proteins: key regulators of T-cell development and function. Nat Rev Immunol. 2005;5(6):472-484.

43. Rengarajan J, Tang B, Glimcher LH. NFATc2 and NFATc3 regulate $\mathrm{T}(\mathrm{H}) 2$ differentiation and modulate TCR-responsiveness of naive $\mathrm{T}(\mathrm{H})$ cells. Nat Immunol. 2002;3(1):48-54.

44. Zhang M, Gong J, Presky DH, Xue W, Barnes PF. Expression of the IL-12 receptor $\beta 1$ and $\beta 2$ subunits in human tuberculosis. Jimmunol. 1999;162(4):2441-2447.

45. van Rietschoten JG, et al. Silencer activity of NFATc 2 in the interleukin- 12 receptor $\beta 2$ proximal promoter in human T helper cells. J Biol Chem. 2001;276(37):34509-34516.

46. Belkaid Y, Rouse BT. Natural regulatory T cells in infectious disease. Nat Immunol. 2005;6(4):353-360.

47. Bolacchi $F$, et al. Increased hepatitis $C$ virus (HCV)-specific $\mathrm{CD} 4{ }^{+} \mathrm{CD} 25^{+}$regulatory $\mathrm{T}$ lymphocytes and reduced $\mathrm{HCV}$-specific $\mathrm{CD} 4^{+} \mathrm{T}$ cell response in $\mathrm{HCV}$-infected patients with normal versus abnormal alanine aminotransferase levels. Clin Exp Immunol. 2006;144(2):188-196.

48. Wohlfert E, Belkaid Y. Role of endogenous and induced regulatory $\mathrm{T}$ cells during infections. JClin Immunol. 2008;28(6):707-715.

49. Vignali DA, Collison LW, Workman CJ. How regulatory T cells work. Nat Rev Immunol. 2008;8(7):523-532.

50. Curotto de Lafaille MA, Lafaille JJ. Natural and adaptive foxp $3^{+}$regulatory $\mathrm{T}$ cells: more of the same or a division of labor? Immunity. 2009;30(5):626-635

51. Weiss JM, et al. Neuropilin 1 is expressed on thymus-derived natural regulatory $\mathrm{T}$ cells, but not mucosa-generated induced Foxp $3^{+} \mathrm{T}$ reg cells. J Exp Med. 2012;209(10):1723-1742.

52. Thornton AM, et al. Expression of Helios, an Ikaros transcription factor family member, differentiates thymic-derived from peripherally induced Foxp $3^{+} \mathrm{T}$ regulatory cells. J Immunol. 2010;184(7):3433-3441.

53. Yadav M, et al. Neuropilin-1 distinguishes natural and inducible regulatory $\mathrm{T}$ cells among regulatory T cell subsets in vivo. J Exp Med. 2012;209(10):1713-1722.

54. Chang JH, Kim YJ, Han SH, Kang CY. IFN-gamma-STAT1 signal regulates the differentiation of inducible Treg: potential role for ROS-mediated apoptosis. Eur J Immunol. 2009;39(5):1241-1251.

55. Feske S, Giltnane J, Dolmetsch R, Staudt LM, Rao A. Gene regulation mediated by calcium signals in T lymphocytes. Nat Immunol. 2001;2(4):316-324.

56 . Bold TD, Banaei N, Wolf AJ, Ernst JD. Suboptimal activation of antigen-specific $\mathrm{CD} 4^{+}$effector cells 
enables persistence of M. tuberculosis in vivo. PLoS Pathog. 2011;7(5):e1002063.

57. Prochazkova J, Pokorna K, Holan V. IL-12 inhibits the TGF-beta-dependent $\mathrm{T}$ cell developmental programs and skews the TGF-beta-induced differentiation into a Th1-like direction. Immunobiology. 2012;217(1):74-82.

58. Holtz-Heppelmann CJ, Algeciras A, Badley $\mathrm{AD}$, Paya CV. Transcriptional regulation of the human FasL promoter-enhancer region. J Biol Chem. 1998;273(8):4416-4423.

59. Hodge S, Novembre FJ, Whetter L, Gelbard HA, Dewhurst $\mathrm{S}$. Induction of fas ligand expression by an acutely lethal simian immunodeficiency virus, SIVsmmPBj14. Virology. 1998;252(2):354-363.

60. Xanthoudakis S, et al. An enhanced immune response in mice lacking the transcription factor NFAT1. Science. 1996;272(5263):892-895.

61. Heyer J, et al. Inefficient termination of antigen responses in NF-ATp-deficient mice. Immunobiology. 1997;198(1-3):162-169.

62. Rengarajan J, et al. Sequential involvement of NFAT and Egr transcription factors in FasL regulation. Immunity. 2000;12(3):293-300.

63. Ranger AM, Oukka M, Rengarajan J, Glimcher LH. Inhibitory function of two NFAT family members in lymphoid homeostasis and Th2 development. Immunity. 1998;9(5):627-635.

64. Turner J, et al. CD8- and CD95/95L-dependent mechanisms of resistance in mice with chronic pulmonary tuberculosis. Am J Respir Cell Mol Biol. 2001;24(2):203-209.

65. Wang Q, Zhou Y, Weiss HL, Chow CW, Evers BM. NFATc1 regulation of TRAIL expression in human intestinal cells. PLoS One. 2011;6(5):e19882.

66. Morra M, Zubiaur M, Terhorst C, Sancho J, Malavasi $\mathrm{F}$. CD38 is functionally dependent on the TCR/CD3 complex in human T cells. FASEB J. 1998;12(7):581-592.

67. Youn HD, Sun L, Prywes R, Liu JO. Apoptosis of $\mathrm{T}$ cells mediated by $\mathrm{Ca} 2+-$-induced release of the transcription factor MEF2. Science.
1999;286(5440):790-793.

68. Vaeth $\mathrm{M}$, et al. Dependence on nuclear factor of activated T-cells (NFAT) levels discriminates conventional T cells from Foxp3+ regulatory T cells. Proc NatlAcad Sci U S A. 2012;109(40):16258-16263.

69. Tone Y, Furuuchi K, Kojima Y, Tykocinski ML, Greene MI, Tone M. Smad3 and NFAT cooperate to induce Foxp3 expression through its enhancer. Nat Immunol. 2008;9(2):194-202.

70. Josefowicz SZ, et al. Extrathymically generated regulatory T cells control mucosal TH2 inflammation. Nature. 2012;482(7385):395-399.

71. Hawwari A, Burrows J, Vadas MA, Cockerill PN. The human IL-3 locus is regulated cooperatively by two NFAT-dependent enhancers that have distinct tissue-specific activities. JImmunol. 2002;169(4):1876-1886.

72. Oh-Hora M, et al. Agonist-selected T cell development requires strong $\mathrm{T}$ cell receptor signaling and store-operated calcium entry. Immunity. 2013;38(5):881-895.

73. Fuchs S, et al. Antiviral and regulatory T cell immunity in a patient with stromal interaction molecule 1 deficiency. JImmunol. 2012;188(3):1523-1533.

74. Bopp T, et al. NFATc2 and NFATc3 transcription factors play a crucial role in suppression of $\mathrm{CD} 4^{+}$ T lymphocytes by $\mathrm{CD} 44^{+} \mathrm{CD} 25^{+}$regulatory $\mathrm{T}$ cells. JExp Med. 2005;201(2):181-187.

75. Beyersdorf N, et al. STIM1-independent $\mathrm{T}$ cell development and effector function in vivo. JImmunol. 2009;182(6):3390-3397.

76. Gwack Y, et al. Hair loss and defective T- and B-cell function in mice lacking ORAI1. Mol Cell Biol. 2008;28(17):5209-5222.

77. Kakeda M, et al. Heat-killed bacillus CalmetteGuerin and Mycobacterium kansasii antigen $85 \mathrm{~B}$ combined vaccination ameliorates dermatitis in a mouse model of atopic dermatitis by inducing regulatory $\mathrm{T}$ cells. $\mathrm{Br} J$ Dermatol. 2012;166(5):953-963.

78. Schoenborn JR, Wilson CB. Regulation of interferon-gamma during innate and adaptive immune responses. Adv Immunol. 2007;96: 41-101.

79. Lee DU, Avni O, Chen L, Rao A. A distal enhancer in the interferon-gamma (IFN $\gamma$ ) locus revealed by genome sequence comparison. J Biol Chem. 2004;279(6):4802-4810.

80. Sakai S, Mayer-Barber KD, Barber DL. Defining features of protective $\mathrm{CD} 4 \mathrm{~T}$ cell responses to Mycobacterium tuberculosis. Curr Opin Immunol. 2014;29:137-142.

81. Lin AA, Tripathi PK, Sholl A, Jordan MB, Hildeman DA. Gamma interferon signaling in macrophage lineage cells regulates central nervous system inflammation and chemokine production. JVirol. 2009;83(17):8604-8615.

82. Barber DL, Andrade BB, Sereti I, Sher A. Immune reconstitution inflammatory syndrome: the trouble with immunity when you had none. Nat Rev Microbiol. 2012;10(2):150-156

83. Shtrichman R, Samuel CE. The role of $\gamma$ interferon in antimicrobial immunity. Curr Opin Microbiol. 2001;4(3):251-259.

84. Grundy S, et al. CRAC channel inhibition produces greater anti-inflammatory effects than glucocorticoids in CD8 cells from COPD patients. Clin Sci. 2014;126(3):223-232.

85. Banaiee N, Kincaid EZ, Buchwald U, Jacobs WR Jr, Ernst JD. Potent inhibition of macrophage responses to IFN $\gamma$ by live virulent Mycobacterium tuberculosis is independent of mature mycobacterial lipoproteins but dependent on TLR2. JImmunol. 2006;176(5):3019-3027.

86. Wolf AJ, et al. Mycobacterium tuberculosis infects dendritic cells with high frequency and impairs their function in vivo. JImmunol. 2007;179(4):2509-2519.

87. Desvignes L, Ernst JD. Interferon-gamma-responsive nonhematopoietic cells regulate the immune response to Mycobacterium tuberculosis. Immunity. 2009;31(6):974-985.

88. Wan Q, et al. Cytokine signals through PI-3 kinase pathway modulate Th17 cytokine production by CCR6 $6^{+}$human memory T cells. JExp Med. 2011;208(9):1875-1887. 